Pecvnia, 8 (2009), pp. 17-70

\title{
Cuestiones esenciales del Análisis Jurídico Financiero de las fórmulas de colaboración público-privada en la financiación de obras y servicios públicos en España
}

\author{
Carolina Blasco Delgado \\ cblasco@ubu.es \\ Universidad de Burgos \\ Derecho financiero y Tributario \\ Facultad de Derecho \\ Hospital del Rey, s/n \\ 09001 Burgos (España)
}

La actual coyuntura de crisis que atraviesa nuestro país nos obliga a plantearnos el modelo en el que queremos que se administren los intereses y necesidades públicas. Los mecanismos de colaboración con el sector privado y la implicación de todos los agentes sociales en la consecución del interés general tendrán probablemente gran protagonismo en el modelo de Administración del futuro, y por consiguiente, en la financiación de bienes y servicios públicos. En la actual coyuntura económica y legislativa la Administración debe asumir un nuevo papel e implicar al sector privado y a los particulares en la financiación de las obras y servicios públicos. Ante esta situación el Derecho financiero no puede permanecer ajeno a estos
The current crisis that our country is suffering forces us to reconsider the model by which we prefer to manage the interests and public needs. Partnership mechanisms with the private sector and involvement of all social partners in achieving general interest, will likely play an important role in the future management model, and therefore, in financing public goods and services. In the current economic and legislative situation, Administration should assume a new role and involve the private sector and individuals in the financing of public works and services. In response, the Financial Law can not remain detached from these changes affecting both public revenue 
cambios que afectan tanto a los ingresos como a los gastos públicos. Es preciso aprovechar las ventajas de esta colaboración y minimizar sus riesgos, pero por encima de todo es necesario articular los mecanismos que hagan realidad el mandato constitucional de que el gasto público realice una asignación equitativa de los recursos públicos Palabras clave: Infraestructuras públicas, colaboración público privada, gasto público, ingresos públicos, equidad. and expenditure. It is important to take advantage of this collaboration and minimize their risks, but above all it is necessary to articulate the mechanisms that translate the constitutional mandate by which public expenditure assigns an equitable allocation of public resources. Key words: Public infrastructure, public private partnerships, public expenditures, public income, equity.

I. INTRODUCCIÓN: LA RELEVANCIA DEL SECTOR PRIVADO EN LA FINANCIACIÓN DE OBRAS Y SERVICIOS PÚBLICOS EN EL CONTEXTO ACTUAL DE CRISIS ECONÓMICA Y FINANCIERA Y CONSECUENCIAS DE SU PARTICIPACIÓN EN EL ÁMBITO JURÍDICO FINANCIERO

La actual situación de crisis mundial y española obliga a tomar decisiones importantes en diversos órdenes que diseñarán el futuro de nuestro país y de sus ciudadanos. Entre estas decisiones, es importante determinar el modo en el que queremos que se administren los intereses y necesidades públicas, y en definitiva, el modelo de Administración del que queremos dotarnos. Este debate que se ha venido planteando entre la doctrina administrativa y económica, se ha plasmado en progresivos pasos legislativos que apuntan hacia un Estado que en el plano económico deja de ser un operador directo y pasa a adoptar un papel regulador, organizador y de control. La aprobación de la Ley 30/2007, de 30 de octubre, de Contratos del Sector Público (en adelante, LCSP), es un hito esencial en esta tendencia al tipificar normativamente la colaboración entre el sector público y privado en la financiación de las obras públicas.

La determinación del papel del Estado, sin embargo, es trascendente en un momento en el que se culpabiliza al fenómeno de la "globalización" de la crisis del modelo de administración contemporánea, y se escuchan con fuerza voces (Dorrego y Martín Vázquez 2009) que hablan de la necesidad de un replanteamiento de las técnicas de intervención de la Administración y de la búsqueda de fórmulas óptimas para satisfacer las necesidades de los ciudadanos.

Para ello, no hay que olvidar que los modelos de Administración a lo largo de la historia se han movido entre dos extremos: 
desde su intervención directa en la producción de bienes y servicios hasta la libertad de los actores privados para satisfacer las necesidades básicas de los ciudadanos que simplemente es vigilada desde las Administraciones. De la observancia de estos modelos, se extrae la conclusión de que ha existido una tendencia cíclica de las administraciones a intervenir en la satisfacción de los intereses públicos, hasta el momento en el que se perciben las consecuencias, en ocasiones nefastas, que provoca su actuación; momento que se convierte en el punto de inflexión que provoca la disminución de su protagonismo en la producción de bienes y servicios, para dar paso en mayor medida a la iniciativa privada. De cualquier modo, lo que parece evidente es que la iniciativa privada ha sido siempre clave y determinante en la producción de bienes y servicios públicos, y en el caso que nos interesa, en la realización de infraestructura y obra pública.

Pues bien, nos encontramos en un momento en el que es determinante iniciar el proceso de recuperación económica y paralelamente, clarificar el modelo de Administración y de satisfacción de las necesidades públicas que resulte más deseable, estableciendo sus perfiles. Un predominio de la iniciativa pública y la aplicación de las soluciones tradicionales para abordar la recuperación pueden generar un incontrolable déficit público, y por ello, la posibilidad de articular fórmulas de Colaboración PúblicoPrivada (en adelante, CPP) que den cabida al sector privado en la provisión de bienes y servicios a los ciudadanos, puede resultar un elemento concluyente para mejorar la prestación de servicios y necesidades públicas e iniciar el camino de la imprescindible recuperación económica.

A estos efectos, y sin perjuicio de una posterior concreción de su significado, adoptamos un concepto amplio del significado de la CPP, incluyendo en el mismo tanto los mecanismos de colaboración institucional como contractual, y dentro de estos últimos, cualquiera que traslade a manos privadas la ejecución, mantenimiento o explotación de obra pública con la intención de posibilitar su financiación, intervenga o no en la misma este sector.

Desde el convencimiento de que los mecanismos en los que la colaboración con el sector privado es más intensa, serán un elemento crucial en la financiación de obras y servicios públicos, y que el futuro de nuestras Administraciones y del cumplimiento de sus fines se desarrollará a través de técnicas de actuación que impliquen la corresponsabilidad de todos los agentes sociales en la consecución del interés general (Fuertes Fernández 2008), se pretende realizar una aproximación a estas fórmulas 
desde una perspectiva fundamentalmente jurídico-financiera, resaltando, específicamente, la importancia de su análisis desde la perspectiva del Derecho financiero, en su doble vertiente, la del ingreso y la del gasto público.

Desde el punto de vista de los ingresos públicos es evidente la necesidad de obtención de recursos para afrontar las inversiones y el posterior mantenimiento que requiere la realización de obras e infraestructuras públicas. La demanda de obras y servicios por parte de los ciudadanos ha llegado a ser ilimitada, y ha provocado la insuficiencia de los recursos presupuestarios disponibles, insuficiencia que se ha hecho más relevante en el momento en el que la crisis económica y la explosión de la "burbuja" inmobiliaria y financiera, han puesto de manifiesto las dificultades de financiación de estos proyectos con cargo a las previsiones presupuestarias anuales.

Por ello, las fórmulas de CPP que durante los últimos años habían adquirido gran protagonismo en nuestro país, fundamentalmente como alternativas que permitían sortear las limitaciones impuestas por los criterios de estabilidad impuestos desde Europa, se perfilan ahora como alternativas que posibilitan la financiación de nuevas obras o servicios, pero bajo un modelo distinto de Administración en el que adquiere un protagonismo clave la corresponsabilidad del sector privado en la consecución del interés público, y en el que tendrá un papel decisivo la colaboración entre el sector público y privado y las fórmulas legales que hacen posible esta colaboración.

Esta alternativa es necesaria en un momento de evidente descenso de recursos presupuestarios y de dificultades de financiación de todos los actores, públicos y privados, y en el que no parece conveniente desde una perspectiva hacendística, económica e incluso sociológica, incrementar los recursos impositivos y tributarios que gravan a empresas y consumidores. Esta realidad se manifiesta ya con crudeza en las previsiones que se perfilan para los presupuestos del próximo ejercicio, y en los que se observa las dificultades de mantener el nivel de inversión necesario, sin incrementar el nivel de déficit y de endeudamiento, incremento que por otra parte alejaría a España de las exigencias de la convergencia europea.

A estos efectos, hay que tener presente que desde Bruselas, la Comisión Europea, con catorce de sus dieciséis miembros de la moneda única con un déficit muy superior al del 3 por 100 recomendado, sigue insistiendo en la necesidad de recuperar este límite, y ha dado como 
plazo a España -al igual que otros países como Francia o Alemania-, hasta el 2013 para volver a la disciplina presupuestaria. España tiene previsto para el cierre del ejercicio 2009 un déficit de 11,2 por 100, aunque el Fondo Monetario Internacional considera que superará el 12 por 100, y sin embargo, se insiste en que empiece a recortar el déficit de forma inmediata realizando cambios en el sistema sanitario o de pensiones, ya que de otro modo se encontrará con fuertes desequilibrios en la próxima década.

Por ello, el Derecho financiero no puede ni debe permanecer ajeno a este escenario de modificaciones en la provisión de bienes y servicios, ya que por una parte hay que poner todos los mecanismos en juego para allegar fondos a las arcas públicas que permitan seguir avanzando en el desarrollo del país, y por otra parte, porque hay que estar atentos a estas fórmulas de colaboración en las que el protagonismo del sector privado altera los sistemas de financiación y ejecución tradicionales de la realización de obra y prestación de servicios públicos con cargo a los recursos públicos presupuestarios, para asegurarnos que las mismas se desenvuelven en el ámbito de la justicia del sistema financiero que garantiza la Constitución Española (en adelante, CE). Se trata de un escenario de financiación complejo en el que las fuentes de financiación de estas infraestructuras pueden provenir de fuentes diversas. En este ámbito es preciso analizar el impacto que puede tener el establecimiento de tarifas en el conjunto del sistema tributario (Juan Lozano y Rodríguez Márquez 2006), ya que ello a nuestro juicio puede tanto provocar una reformulación de la naturaleza y estructura del conjunto de prestaciones de carácter público, como a un incremento impositivo que no tenga en cuenta las políticas de tarificación cada vez más generalizadas.

Por ello, es preciso explorar todas las posibilidades existentes y examinarlas desde la conveniencia de apostar por los principios contributivo o retributivo en la financiación de estas obras y servicios públicos.

Esta reflexión nos lleva al estudio de esta realidad desde la perspectiva del gasto público, ya que como se expone el escenario de crisis económica parece aconsejar, al menos inicialmente, mantener, e incluso, incrementar, el volumen de obra pública a promover y ejecutar por las Administraciones. De este modo, se podría seguir sosteniendo, y dimensionando, uno de los que han venido siendo claves en la economía.

La financiación privada, y más concretamente las fórmulas de CPP, se perfilan como una vía alternativa para acometer obras públicas, si 
bien, hay que tener en cuenta que en la actualidad la viabilidad de estos modelos también atraviesa dificultades por los problemas de financiación que el sector encuentra en el mercado financiero. Por ello, el apoyo de las Administraciones será clave para la financiación de estos proyectos, obligando a priorizar y seleccionar cuidadosamente los que en mayor medida respondan a las políticas y necesidades sociales. En este ámbito, consideramos que es necesario articular los sistemas que hagan realidad el mandato constitucional del artículo 31.2 de nuestra Carta Magna, que establece que el gasto público realizará una asignación equitativa de los recursos públicos y su programación y ejecución responderá a los principios de eficiencia y economía, así como el previsto en el artículo 133.4, que como es sabido recoge el principio de reserva de ley en el gasto público. Por ello, es necesario recordar el significado de estos principios a los que se someten las decisiones de gasto y analizar en qué medida la utilización de la CPP es respetuosa con su consecución.

Por todo lo expuesto, es preciso abordar con rigor las fórmulas que nos permitan mantener este complejo equilibrio, y en esta elección, el análisis jurídico financiero de las CPP resulta imprescindible. A estos efectos, hay que tener en cuenta que no nos encontramos ante un fenómeno nuevo en nuestro país, la CPP se viene utilizando desde mediados de los años noventa para la financiación de obras públicas, utilización que ha sido refrendada por las sucesivas modificaciones legislativas que han dado cobertura legal a vías que se iban utilizando para su ejecución. Ahora bien, la coyuntura económica y legislativa actual posiblemente sea la más idónea para su utilización, tratando de aprovechar al máximo las ventajas de la CPP y minimizando sus riesgos. Para ello, será preciso: analizar las fórmulas para financiar el coste de la ejecución de obras públicas y su posterior mantenimiento; decidir si su financiación se debe acometer por todos los contribuyentes o por los que se benefician en mayor medida de su ejecución; seleccionar qué inversiones pueden acometerse mediante CPP; o más concretamente, cuál es el método más conveniente para su ejecución y financiación. Todas estas cuestiones están estrechamente vinculadas tanto con los ingresos públicos (principio contributivo o retributivo, o la exigencia de tasas, contribuciones especiales y tarifas), como con el gasto público (asignación equitativa de recursos públicos, eficiencia y economía en la programación y ejecución del gasto público y papel relevante de la ley en la adopción de decisiones vinculadas con las necesidades públicas prioritarias), así como con otras cuestiones entroncadas más directamente con la institución presupuestaria. 
Estamos, por tanto, ante una realidad jurídica compleja, en la que los condicionamientos políticos y económicos son claves, y que parece necesario abordar globalmente desde la doble vertiente del Derecho financiero, para dar noticia de los aspectos que se consideran más relevantes o problemáticos. No obstante, se trata de un tema de carácter interdisciplinar que obliga a valorar otros aspectos de las fórmulas de CPP, desde los estrictamente contables hasta la regulación de la materia en otras ramas del ordenamiento jurídico, lo que pone de manifiesto la unidad esencial del mismo.

Para dar noticia de las cuestiones sistematizamos su análisis en tres apartados que abordan sucesivamente, en primer lugar, el papel de las administraciones públicas como proveedoras de obras y servicios públicos y la importancia que la fórmula de financiación tiene en la elección del método para su ejecución. En segundo término, en el contexto de insuficiencia de recursos públicos expuesta se analizarán las posibilidades actuales de financiación de obras públicas y las oportunidades que las fórmulas de colaboración público privada tienen en este ámbito. Y finalmente, y desde la perspectiva del gasto público, se analiza la CPP desde la perspectiva de los controles a los que nuestra legislación somete las decisiones de gasto de las administraciones, realizando un estudio de estas fórmulas a la luz de los principios que informan el gasto público, así como su configuración y programación en el presupuesto.

II. LA ADMINISTRACIÓN PÚBLICA COMO PROVEEDORA DE OBRAS Y SERVICIOS PÚBLICOS: INFLUENCIA DE LA FINANCIACIÓN EN LA ELECCIÓN DEL MÉTODO PARA SU EJECUCIÓN

\section{A. Las obras públicas: delimitación conceptual}

Parece evidente que la doctrina mayoritaria coincide en que la puesta en marcha de una certera política de obras públicas contribuye al crecimiento de un país, repercutiendo tanto en su productividad económica, en su competitividad y en el incremento del bienestar social (Valcárcel Fernández 2007), y más en el momento por el que atraviesa nuestro país, en el que, como ya se ha expuesto, decisiones acertadas en ese ámbito serán un elemento clave para la recuperación económica.

En efecto, el Libro Blanco sobre el Crecimiento, Competitividad y Empleo (Comisión Europea 12/1993) puso ya hace años de manifiesto la conexión existente entre infraestructuras y competitividad 
de la economía. Idea reiterada posteriormente por la Estrategia de Lisboa, que en nuestro país se concretó en el Programa Nacional de Reformas de 2005 y en la que se manifiesta la importancia de las infraestructuras como mecanismo de provisión que se han de adaptar al contexto de la estabilidad presupuestaria, considerando que las fórmulas de CPP son un instrumento básico para la dotación de infraestructuras y provisión de servicios públicos. Posteriormente, también desde Europa, el propio Consejo ha señalado que el recurso a mecanismos privados de construcción de las infraestructuras es determinante, señalando que:

... las inversiones en infraestructuras favorecerán el crecimiento e implicarán una mayor convergencia en los planos económico, social y medioambiental (...) El Consejo Europeo destaca la importancia de la realización de los proyectos prioritarios en materia de redes de transporte y de energía e invita a la Unión y a los Estados miembros a que prosigan su esfuerzos de inversión y fomenten asociaciones entre los sectores público y privado (Consejo Europeo 2005).

Por otra parte, aunque los principales impulsores de esa política han venido siento los poderes públicos, y de modo particular, las administraciones públicas a quienes ha correspondido un papel protagonista en su definición, ya se ha adelantado que un nuevo modelo de corresponsabilidad en la consecución del interés público ofrece un nuevo rol al sector privado, y brinda posibilidades de financiación para la consecución de obras y servicios públicos. El máximo exponente de este cambio se ha plasmado en la nueva LCSP en la que se regula el contrato de colaboración entre el sector público y el sector privado al que posteriormente se hará referencia.

Jurídicamente, como hemos tenido ocasión de comprobar, las opciones para la ejecución de la política de obras públicas son diversas, por lo que con la intención de aproximarse al tema parece conveniente en primer lugar delimitar el concepto de obra pública y conocer su vinculación con las técnicas del servicio y de dominio público. Además hay que concretar las principales alternativas para su ejecución, y sus últimas novedades, destacando la importancia que la financiación tiene en su elección, y prestando especial atención a las posibilidades que ofrecen el ya clásico contrato de concesión de obra pública o el más reciente de colaboración entre el sector público y privado, tal y como los define la nueva LCSP.

Centrándonos en el concepto de obra pública, existen múltiples realidades susceptibles de ser integradas dentro de este concepto, 
por lo que es preciso ofrecer un concepto jurídico de la misma desde el que afrontar el estudio de su financiación y proponer cuáles son más permeables a las fórmulas de financiación con colaboración público-privada (Valcárcel Fernández 2006).

En esta tarea se pone de manifiesto que el elemento finalista es el más relevante de su definición: esto es, el interés público o colectivo que persigue la obra pública. Ello no impide que las obras públicas puedan ser contempladas desde la perspectiva de su resultado, y en este sentido, su relación con la técnica del dominio público es muy estrecha. La obra pública, también puede enfocarse desde el punto de vista de la actividad que la genera, perspectiva que la vincula con la actividad que desarrolla la administración pública que debe proveer servicios públicos, ya que es la competente para ejecutar las obras necesarias para su desarrollo.

Desde la primera perspectiva, esto es, desde el interés público o colectivo que mueve la realización de obra pública, se hace necesario individualizar la obra pública del dominio público en tanto que una identificación absoluta de ambas técnicas puede llevar a hacer inviables las fórmulas alternativas de financiación a las que se hace alusión, debido al estricto régimen jurídico que acompaña al dominio público, y que como es sabido, se caracteriza por su inembargabilidad, inalienabilidad e imprescriptibilidad.

Desde el segundo enfoque, la actividad tendente a la consecución de obras públicas exige aludir a los distintos modos de realizar obra pública, y fundamentalmente, a los modos contractuales, destacando cómo en función de la opción elegida, las fórmulas para su financiación difieren e inciden de forma diversa sobre el presupuesto del ente público.

B. Mecanismos para la realización de obras públicas y relevancia de la financiación en su elección

Teniendo en cuenta lo previamente expuesto es preciso hacer referencia a los mecanismos de ejecución de obras públicas previstos en la legislación vigente y en concreto en la LCSP. Esta referencia ha de realizarse de forma genérica en un trabajo de estas características en que lo determinante es resaltar los aspectos jurídicos financieros que conlleva la utilización de fórmulas de CPP para su realización y ejecución.

Cuando la Administración se plantea la ejecución de una obra puede ejecutarla directamente o contratar con terceros su realización. En 
el primer supuesto, estamos ante lo que la doctrina administrativa mayoritaria considera ejecución directa de obras públicas, y en el segundo realización indirecta.

A su vez, dentro de la ejecución directa de obras públicas, éstas pueden acometerse por la propia Administración o a través de organismos públicos o creación de entes instrumentales a los que se encargue su ejecución. Estos entes, pueden contratar con terceros la realización de las obras -opción que se denomina ejecución directa diferenciada-, posibilidad que cobró hace casi dos décadas gran fuerza en España en todos los niveles territoriales, fundamentalmente a través de la creación de sociedades mercantiles, hasta el punto que este mecanismo adoptó el nombre de "modelo español" entre los sistemas utilizados para sortear los límites del endeudamiento impuestos desde Europa.

La circunstancia que motivó esta tendencia, además de la búsqueda de mayor eficacia en la gestión de la actividad y a la intención de flexibilizar la aplicación de las normas de contratación pública -se regía por las normas del derecho privado-, fue que este modelo posibilitaba alcanzar los criterios de convergencia necesarios para acceder a la tercera fase de la Unión Económica y Monetaria, puesto que las normas contables entonces permitían no computar sus deudas en el cálculo del déficit público.

En otro orden de cosas, hay que tener en cuenta que si estas entidades proceden a contratar con terceros la realización de las obras, ya no estaríamos ante un supuesto de ejecución directa sino de ejecución indirecta de obras públicas.

Por lo que se refiere a la ejecución indirecta de obras públicas, se presentan varias alternativas: la celebración de un contrato de obra, de un contrato de gestión de servicios públicos, de uno de naturaleza concesional o la reciente puesta en marcha del contrato de colaboración entre el sector público y privado.

El contrato de obras se regula en el artículo 6 de la LCSP y en él es la Administración titular de la obra la que asume los riesgos derivados de su construcción y explotación y la financia con cargo a los créditos presupuestarios.

El contrato de concesión de servicios públicos, es una modalidad del contrato de gestión de servicios prevista en el artículo 253, a) de la LCSP por la que el contratista gestiona un servicio a su propio riesgo y ventura, y en la que dicho contratista puede estar obligado a construir 
las obras o instalaciones que son necesarias para la correcta prestación del servicio. Estas obras revierten a la Administración al extinguirse la concesión, tal y como se dispone en el artículo 259.1 de la LCSP.

Por su parte, el contrato de concesión de obra pública se define en el artículo 7 de LCSP como el que tiene por objeto la realización por el concesionario de una obra -así como la restauración y reparación de construcciones existentes, así como la conservación y mantenimiento de los elementos construidos-, que responda a las necesidades especificadas por la entidad del sector público contratante, y en el que la contraprestación de aquél consiste, o bien únicamente en el derecho a explotar la obra o bien en el derecho acompañado del de percibir un precio.

Por tanto, la distinción entre este contrato y la figura del contrato de obras se difumina en la medida que en el primero la compartición de riesgos se mitigue por la asunción de los riesgos del contrato por la Administración, bien cuando existen aportaciones a la construcción o a la explotación, o cuando asume parte del precio de la obra aunque desvinculado del riesgo de explotación. A su vez, se diferencia de la concesión de servicios públicos en que en éste último la realización de las obras es accesoria respecto del servicio que es el objeto principal del contrato.

Pues bien, la mayoría de los modelos de financiación de obras públicas se han venido reconduciendo bien a la fórmula del contrato de obra o a los modelos concesionales, por lo que pasamos a realizar una referencia a los mismos.

Por lo que se refiere al contrato de obra, además de la tradicional contratación de obra pública en la que el precio que satisface la Administración por la obra se va realizando a cargo de créditos presupuestarios, mediante la emisión de certificaciones de obra a cuenta del precio total, y en el que estas cantidades figuran como deuda en el presupuesto de la entidad contratante, aparece una variante de este modelo, llamado "modelo de abono total del precio" o "modelo alemán" que pretende evitar que se computen como deuda los pagos parciales que se realizan a medida que se va recibiendo la obra en el contrato de obra tradicional. De este modo, en la modalidad de abono total del precio el pago al contratista se realiza en el momento en el que se recibe la obra en su totalidad. Por tanto, es el contratista el que ha de buscar financiación durante el período de construcción de la obra, asumiendo a su vez los riesgos de esta fase, y por su parte, la Administración además 
de conseguir diferir el pago de la obra al ejercicio en el que ésta se recibe, controla su precio, ya que éste se pacta en el momento inicial.

Esta variante encaja tanto en los sistemas de financiación con cargo a los créditos presupuestarios como en los que no tienen un efecto directo sobre el presupuesto al financiarse por los usuarios de las obras, ya que es también posible que la financiación de los pagos se realice con cargo a un peaje por el uso de una infraestructura, siempre que en el momento de la extinción del contrato, la Administración decida explotar la obra realizada, bien directamente, en cuyo caso daría lugar a un precio público o indirectamente, generando una tarifa para el usuario.

En nuestro derecho positivo, esta modalidad fue incorporada con carácter excepcional a nuestro derecho positivo en la Ley 13/1996, de 30 de diciembre, de Medidas Fiscales, Administrativas y de Orden Social, limitada a una serie de infraestructuras: carreteras, ferroviarias, hidráulicas, en la costa y medioambientales, y siempre que en cada caso no se superaran determinados umbrales económicos. A pesar de su carácter excepcional, la LCSP recoge una referencia a esta variante en su artículo 111.

Por lo que se refiere al modelo concesional, tal y como ya se ha expuesto, las modalidades son la gestión de servicios públicos y la de obra pública (Ariño Ortiz 2005) y en ambos casos, a pesar de las antedichas diferencias, tienen como factor común que como contrapartida a la prestación del contratista de la obra se permite la gestión privada de unos servicios que de otra forma serían prestados por la Administración concedente. En estas figuras, la financiación privada es compatible con la financiación pública, como sucede en el denominado modelo de "peaje en sombra", en el que el precio pagado por el uso de la obra lo realiza en todo o en parte la Administración.

Estas variantes convierten esta figura en un mecanismo de financiación de obras públicas con multitud de posibilidades, ya que pueden realizarse con recursos presupuestarios o financiarse con cargo a los usuarios de los servicios a los que las obras están afectos.

Por lo que respecta a la concesión de obra pública con aportaciones públicas bien a la construcción o a la explotación, hay que destacar que para que este contrato no quede desvirtuado es preciso encontrar un equilibrio entre estas aportaciones y uno de los elementos característicos de la concesión: el riesgo y ventura del concesionario. En efecto, se trata de encontrar el equilibrio entre la captación de fondos privados para la realización de obras públicas, la rentabilidad del 
concesionario limitando la asunción de riesgos y, finalmente, el interés de los usuarios. Ahora bien, esta difícil interrelación provoca que estos modelos tengan efectos sobre la distribución de los recursos públicos, en la medida que decisiones de inversión que se adoptan hoy pueden conllevar compromisos de gastos que afectarán a posteriores ejercicios presupuestarios, produciéndose un diferimiento del gasto.

Por otra parte, si se diluye en exceso el riesgo del concesionario sin que llegue a asumir un mínimo del riesgo de la construcción, de disponibilidad o de demanda, la construcción del activo, según las reglas de la contabilidad nacional tendrá efectos en el cómputo de la deuda pública, no alcanzándose uno de los objetivos que se perseguía.

Además, esta figura contempla la posibilidad de diversificar la financiación; financiación que podrá ser pública (subvenciones al precio, anticipos reintegrables, préstamos participativos, subordinados o de otra naturaleza), o privada (emisión de obligaciones, la titulización de créditos, la hipoteca de la concesión o créditos participativos), con la intención de facilitar la utilización de variadas fórmulas de financiación al inversor privado que estimulen su colaboración en estos proyectos.

Las fórmulas concesionales han sido muy utilizadas en el ámbito anglosajón en sus diversas variantes (Acerete Gil 2004) pero cuando se han querido trasladar a nuestro sistema continental han encontrado muchas limitaciones derivadas, por ejemplo, de nuestra concepción del dominio público que no encajaba con mecanismos de construcción en los que la propiedad de la obra estaba en manos privadas. En nuestro país, no obstante estas fórmulas se regularon inicialmente por algunas CC.AA., aunque en el ámbito estatal no fue hasta la Ley 13/2003, de 23 de mayo, reguladora del contrato de concesión de obra pública, cuando se abrió esta posibilidad que se mantiene y amplia en la nueva LCSP a la que se hará posteriormente referencia. En efecto, en 2003 se dio carta de naturaleza a las fórmulas de colaboración público-privada en su versión no institucionalizada, y abrió las posibilidades de uso de esta figura por parte de las administraciones públicas, posibilidades que se han utilizado profusamente hasta sobrepasar sus perfiles, lo que de nuevo puso de manifiesto la insuficiencia de la nueva regulación para los proyectos de las Administraciones cada vez con menos recursos y obligadas a atender nuevas exigencias colectivas. En este ámbito aparece de nuevo contrato de colaboración entre el sector público y privado de la LCSP. 
Precisamente, el contrato de colaboración entre el sector público y privado se define en el artículo 11 de la LCSP como aquel en que una Administración Pública encarga a un empresario por un período determinado, la realización de una actuación global e integrada que, además de la financiación de inversiones inmateriales, de obras o de suministros necesarios para el cumplimiento de determinados objetivos de servicio público o relacionados con actuaciones de interés general, comprenda alguna de las prestaciones previstas y, entre ellas, la construcción de obras y explotación de obra, instalación o transformación de obras junto con equipos, sistemas, y productos o bienes complejos.

Por lo que respecta al modo en el que el contratista colaborador va a recuperar el coste de la inversión, el artículo 11.4 de la LCSP sólo prevé el pago de un precio que se satisfará durante toda la duración del contrato y que podrá estar vinculado al cumplimiento de determinados objetivos de rendimiento.

Este contrato de aplicación subsidiaria tiene un objeto que engloba todos los anteriores y se puede acudir a él, según lo estipulado en el artículo 118 de la LCSP, cuando la complejidad del contrato impida definir antes de la licitación los medios técnicos proyectados o establecer los mecanismos jurídicos o financieros para llevarlo a cabo. La doctrina más reciente considera que lo determinante de su utilización será la complejidad que en el orden financiero pueda presentar la realización de un proyecto, o mejor dicho, las dificultades de financiar el contrato, esto es, la insuficiencia de recursos públicos para hacer frente a la ejecución del proyecto (Jiménez Díaz 2009).

Esta figura facilitará vías de financiación en los proyectos que no son susceptibles de explotación comercial y en los que no puede repercutirse el coste a los ciudadanos, debiendo de asumir su coste la Administración, que podrá prorratear el mismo a lo largo de la vida del contrato. Por tanto, es de nuevo la financiación, la pieza clave de la elección de este contrato.

Hasta ahora se han analizado todos los mecanismos existentes para la realización de obras destacando su financiación: pública, de los particulares o del sector privado, y mixta; clasificación que es prácticamente coincidente con los efectos que estos mecanismos tienen sobre el presupuesto de los Entes Públicos.

De este modo, tienen una incidencia directa sobre el presupuesto, en tanto que se financian con recursos públicos: la ejecución 
directa de obras públicas, el contrato de obra tradicional, la variante del sistema llave en mano, la concesión administrativa con retribución articulada mediante "peajes en sombra", la creación de sociedades a las que se destinan aportaciones públicas y el contrato de colaboración entre el sector público y privado. Por su parte, si las sociedades gestionan obras cuyo coste se sufraga por precios pagados por los usuarios de las obras o servicios, o en el caso de concesiones de obras y servicios que se financian con la gestión del servicio por el contratista, cubriendo con ello el coste de la obra, estamos ante modalidades que no tendrían efectos sobre el presupuesto. En muchos supuestos, como se ha comprobado, la posibilidad de simultanear tanto la financiación pública como la financiación por los particulares, hace que no encaje en una de estas clasificaciones sino que participe de ambas.

Otro factor importante, además del carácter público o privado de la financiación y de su incidencia o no en el presupuesto, es la posibilidad que estos mecanismos otorgan de diferir el coste de la obra, como sucede en el contrato con abono total del precio, o bien de convertir inversión en gasto difiriendo también su pago como sucede en el contrato de colaboración entre el sector público y privado.

Por consiguiente, en todos los mecanismos de realización de obra pública expuestos es determinante el modo de afrontar su financiación. A estos efectos, hemos visto que con carácter general las posibilidades de financiación de estos proyectos puede articularse: en primer lugar, con cargo a créditos presupuestarios; en segundo término, mediante cánones pagados por los usuarios del servicio, aunque estos cánones también puede ir acompañados de aportaciones de los poderes públicos; en tercer lugar, cuando no cabe la recuperación del coste de la inversión mediante el pago de un canon, el poder público debe financiar una parte del mismo para compensar los beneficios sociales derivados del mismo; y finalmente, se puede acudir a la compra de bienes y servicios por los poderes públicos, de manera que el socio privado se responsabilice de la inversión y el pago se efectúe en función de la realización de la obra o servicio.

Ahora bien, la decisión de cuál debe ser la forma de ejecutar la obra pública, que estará mediatizada por la disponibilidad de recursos por parte de la Administración promotora o por el modo en el que la financiación de la obra no incremente su endeudamiento, debe tener también en consideración que la elección tiene efectos diferentes frente a los usuarios de estos servicios, ya que en unos casos el coste recaerá 
sobre ellos directamente, y en otros, sobre los contribuyentes en su conjunto, por lo que en una primera aproximación a este tema se puede decir que parece razonable utilizar estos mecanismos basados en el principio contributivo en la medida que se trate de obras y servicios que no tengan carácter esencial.

Es el momento de abordar estas cuestiones relativas a los efectos que tienen la utilización de fórmulas de CPP así como analizar vías alternativas de financiación de obras públicas que pueden resultar de interés ante la actual insuficiencia de los recursos públicos, en definitiva, analizamos desde la perspectiva del ingreso la necesidad de la utilización de CPP para la financiación de obras públicas aunque advirtiendo de sus efectos y consecuencias y ofreciendo otras vías poco utilizadas en el ámbito tributario que pueden allegar recursos para la consecución de estos objetivos.

III. INSUFICIENCIA DE RECURSOS PÚBLICOS PARA FINANCIAR OBRAS Y SERVICIOS PÚBLICOS: ALTERNATIVAS DE CPP PARA SU FINANCIACIÓN Y EJECUCIÓN

Una vez que se ha puesto de manifiesto la conveniencia de que los entes públicos promuevan la realización de obra pública por los beneficios que esta situación provoca en la economía, se ha aludido brevemente a los mecanismos con los que cuentan las Administraciones para su realización, y se ha recordado, la relevancia que el modelo de ejecución elegido tiene en las fuentes de financiación de las obras, es preciso analizar las posibilidades de obtención de recursos para hacer frente a su realización. De este análisis será preciso concluir su viabilidad y su suficiencia en el contexto económico y político actual.

\section{A. Insuficiencia de recursos públicos y limitaciones para financiar obras públicas}

Como hemos tenido la oportunidad de recordar al principio de este trabajo, en el ámbito del Estado del Bienestar las consecuencias políticas que implica cualquier intento de minorar los logros que los ciudadanos han alcanzado parecen inasumibles, pero esta situación no encaja con la actual disminución de recursos públicos que han experimentado las administraciones públicas y con las exigencias que 
demandan los ciudadanos en el contexto de la crisis que atraviesa nuestro país.

Apuntábamos en líneas precedentes, que en las teorías económicas keynesianas, el Estado debía tener un papel claramente intervencionista y estabilizador, siendo incluso recomendable recurrir a la emisión de deuda para financiar el gasto público si fuera necesario. La consecuencia de la aplicación de este modelo fue un importante incremento de la deuda pública y del déficit en los países desarrollados y provocó la recomendación contraria, la limitación de la deuda por parte de instituciones nacionales e internacionales.

A este marco de demandas ilimitadas de bienes y servicios por parte de los ciudadanos y un entorno económico mediatizado por las restricciones de generación de déficit y deuda, se añade el rechazo social que tradicionalmente se ha manifestado a que se incrementen los impuestos y a que se apliquen políticas de recuperación de costes de los servicios prestados por las administraciones públicas, sobre todo cuando se consideran que éstos son esenciales y venían prestándose en régimen de gratuidad. Rechazo que se acrecienta en la situación económica actual.

Por consiguiente, es necesario conocer en profundidad las restricciones existentes para la obtención de recursos públicos para poder abordar posteriormente el importante papel que en la financiación de determinadas obras públicas pueden tener los usuarios y beneficiarios de las mismas.

Estas limitaciones afectan a las dos vertientes de la actividad financiera, la obtención de ingresos y su aplicación al gasto público, y podrían sistematizarse en función de su carácter normativo o sociológico. Dentro de las primeras, se puede diferenciar entre las impuestas por la normativa comunitaria o interna.

Por lo que respecta a las limitaciones que afectan al gasto público hay que aludir a las provocadas por nuestra pertenencia a organizaciones supranacionales y de nuestra propia legislación presupuestaria interna. La primera conlleva que estemos sometidos a la disciplina presupuestaria que se adopta en el seno de la Unión Europea y las normas de contabilización de acuerdo con la disciplina establecida por EUROSTAT-95.

Por otra parte, la legislación presupuestaria española se apoya sobre un compromiso de estabilidad presupuestaria, basado en los principios de plurianualidad, transparencia y eficiencia, buscando una 
mayor racionalización del proceso presupuestario. En este ámbito, hay que destacar dos aspectos importantes: la plurianualidad limita a tres ejercicios los escenarios plurianuales de programación del sector público y el límite cuatrienal para la adquisición de compromisos de gastos plurianuales, con excepción de los casos especialmente justificados.

Además de estas restricciones de carácter general, es preciso aludir a limitaciones más concretas, como las que encontramos en los artículos 86 y 87 del Tratado de la Unión Europea que limitan las ayudas de estado a empresas total o mayoritariamente participadas por entes públicos, con la finalidad de no alterar la competencia en los mercados.

Desde la perspectiva de los ingresos, es preciso referirse en primer lugar a una limitación que aunque no tiene carácter legal sí un importante componente sociológico que en ocasiones hace inviable su utilización: es evidente el rechazo por parte de los contribuyentes a aceptar incrementos impositivos, así como las consecuencias políticas que esta situación genera, y más aún en una situación de crisis económica como la que actualmente se atraviesa.

En efecto, los impuestos personales diluyen la relación entre la producción de los recursos, las necesidades que los provocan y las preferencias y valoraciones de los usuarios/beneficiarios, y suponen que los protagonistas del proceso presupuestario lo sean también de la asignación de estos recursos a bienes y servicios. Sin embargo el establecimiento de tributos finalistas y afectados hacen que el coste del bien recaiga sobre quien genera y utiliza el servicio. Esta opción, a pesar de ser cada vez más aceptada por los contribuyentes, no excluye, por ejemplo, el rechazo generalizado al establecimiento de contribuciones especiales para financiar las obras locales, ámbito en el que estos tributos tienen carácter afectado.

Junto a estos aspectos que limitan la obtención de recursos tributarios encontramos otros de carácter legal, en tanto que nuestro ordenamiento interno establece limitaciones respecto de la elección de las figuras que pueden financiar el coste de las obras públicas cuando se decide que parte sea financiado por los usuarios (Cayón Galiardo y Almudí Cid 2008). En efecto, existen imperativos constitucionales -exigencias de las prestaciones patrimoniales de carácter público-, y legales para la exacción de determinados recursos, en tanto que su régimen jurídico impone ciertas limitaciones materiales y competenciales para su establecimiento.

Adicionalmente, en algunos sectores como pueden ser las carreteras y el agua, la normativa comunitaria y también la interna 
establecen determinadas exigencias que afectan a su financiación, así, por ejemplo, en el ámbito de la política de aguas, las legislaciones estatales, por exigencias comunitarias, han de fundamentarse en la recuperación del coste de los servicios relacionados con el agua.

Precisamente, la recuperación de costes en la prestación de servicios merece una atención especial en tanto que tal y como se ha expuesto, se va aceptando en mayor medida por los ciudadanos en tanto que les permiten vincular sus contribuciones con los servicios recibidos. En este ámbito, hay que llamar la atención sobre la utilización de algunos recursos tributarios y otras prestaciones patrimoniales de carácter público y valorar su exacción desde la perspectiva de los principios constitucionales que informan su establecimiento.

B. Los usuarios y los beneficiarios en la financiación de obras y servicios públicos

A pesar de las limitaciones expuestas, las Administraciones actualmente cuentan con un amplio margen para decidir el mecanismo de ejecución de una obra pública aplicable a cada caso y para elegir el mecanismo para afrontar su coste. En función del modelo por el que se opte para la financiación de la obra pública se realizará con cargo a los recursos presupuestarios existentes en el momento de realización de la obra, o bien, trasladando su coste y mantenimiento a los usuarios, o incluso, a futuros contribuyentes. En ocasiones, el mecanismo de financiación determina la propia realización de la obra pública.

En este escenario, de entre todas las opciones posibles habrá que elegir la que conjugue en mayor grado la satisfacción del interés general con el máximo aprovechamiento de los recursos de las Administraciones, y en este juego, en ocasiones, puede resultar relevante que parte del coste de las obras públicas lo asuman los usuarios o beneficiarios de las obras y servicios públicos.

En este sentido, hay que señalar que en tanto que el objeto de estudio de este trabajo lo constituye el análisis jurídico-financiero de los mecanismos de financiación de las obras públicas, que como se ha expuesto se caracterizan precisamente por el interés general y colectivo que subyace en su realización, inicialmente parece razonable que su financiación se acometa con cargo a los ingresos públicos generales, y fundamentalmente, impositivos. Ahora bien, en tanto que algunas obras públicas son susceptibles de producir, además de ese interés colectivo en 
su realización, beneficios individuales, inicialmente puede mantenerse que su financiación se realice en mayor medida por quienes usan o se benefician de la obra o servicio.

En estos casos se pretende acercar el gasto a quien lo genera, aunque a su vez, y en función del modelo de financiación por el que se opte, y dependiendo de que la obra o servicio se ejecute y preste directamente por la Administración o por sujetos privados que normalmente colaboran en su financiación, se pueden generar distintos tipos de contraprestaciones con distinto régimen jurídico y cuyos aspectos más relevantes se tratan de exponer en las siguientes líneas.

a) Los principios contributivo y retributivo en la financiación de obras públicas

Nos encontramos por tanto ante el debate abierto tras la reforma de la Directiva 1999/62/CE, que amplió las tasas y peajes elegidos por el uso de autopistas, y a su vez, autorizó a los gobiernos a establecer compensaciones en el impuesto de circulación, sobre si es preciso una modificación del papel que los usuarios y beneficiarios han de tener en la financiación de las infraestructuras (Juan Lozano y Rodríguez Márquez 2006).

Por ello es preciso analizar la mayor o menor adecuación de los diversos ingresos públicos de derecho público para sufragar el gasto público que se precisa para la construcción de obra y prestación de servicios públicos. Así, los impuestos serían los más adecuados para financiar gastos indivisibles, las contribuciones especiales gastos en parte divisibles y en parte no divisibles, y las tasas se corresponderían con los gastos divisibles. Por consiguiente, si se adopta un modelo contributivo los impuestos serán el principal recurso a emplear para cubrir esos costes, con independencia incluso de la forma de gestión del servicio. No obstante, también es posible que parte del coste de los bienes y servicios se encargue a sus usuarios o beneficiarios, optando por tanto por el principio retributivo. En este ámbito adquieren gran relevancia las tasas, las contribuciones especiales, los precios públicos y las tarifas o precios privados. Su utilización, en ocasiones, depende del modo de financiación de la obra pública, como sucede en el caso de las contribuciones especiales o las tarifas. En algunos supuestos, es posible simultanear su utilización.

Pues bien, consideramos que en un Estado en el que la cobertura de las necesidades de los ciudadanos es muy elevada y en el que 
una coyuntura económica desfavorable obliga a dedicar un importante montante de ingresos públicos al gasto social, el principio retributivo adquiere un mayor protagonismo y puede potenciar el incremento de instrumentos enmarcados en esta teoría, como las tasas, contribuciones especiales, precios públicos, tarifas, precios privados y otras figuras afines, aunque el principio del beneficio aconseja que sólo sean financiados de esta manera los bienes y servicios o actividades administrativas que sean beneficiosos para determinados sujetos (Ruiz Garijo 2008). En la medida que su provisión repercuta sobre la colectividad estará justificado que se financien además con ingresos obtenidos de la contribución de todos los ciudadanos al sostenimiento de los gastos públicos.

En este ámbito, hay que destacar la adecuación de las tasas y las contribuciones especiales para financiar determinadas obras y servicios públicos en tanto que su hecho imponible precisamente se identifica con la utilidad o beneficio que la actividad o actuación de la administración genera en los sujetos pasivos. En el caso de que el beneficio o utilidad proceda de la prestación de un servicio o de la autorización para un aprovechamiento especial del dominio público estaremos ante una tasa, y si el hecho que lo provoca es la realización de una obra pública o el establecimiento o ampliación de un servicio se tratará de una contribución especial. En esto caso, el importe a satisfacer por el beneficiario está justificado y mediatizado por los principios del beneficio, y en el caso de la tasa por el de equivalencia.

La exigencia de precios públicos tiene la misma finalidad, aunque en estos casos, en tanto que no son tributos, y por lo tanto su exacción no es coactiva, el principio retributivo adquiere toda justificación ya que son auténticas contraprestaciones por los servicios públicos de recepción voluntaria que además son prestados en concurrencia con el sector privado. Su importe no está limitado como en el caso de las tasas por el principio de equivalencia, que exige que no supere el coste del servicio.

Por lo que respecta a las tarifas hay que señalar que no forman parte del presupuesto de los entes públicos y se fundamentan en el principio retributivo en tanto que el usuario del servicio retribuye a quien se lo presta, que puede y suele ser un "gestor privado". Tienen por tanto, distinto régimen jurídico, distinta finalidad y distintos componentes cuantificadores, por lo que se ha venido perfilando como la figura más apropiada para aludir al precio que recibe el contratista por la gestión indirecta del servicio prestado. 
En relación con esta figura hay que señalar que a pesar de la opinión que desde hace años viene sosteniendo parte de la doctrina (García de Enterria 1953) en la línea de considerar que tarifas eran tasas y no precios, el Tribunal Supremo ha refrendando durante mucho tiempo la diferencia entre el poder tarifario y el poder tributario. Esta situación se ha modificado con la última doctrina del Tribunal Constitucional (SSTC 102/2005, de 20 de abril; 121/2005, de 10 de mayo y 122/2005, de 11 de mayo) que respecto de la naturaleza jurídica de las tasas portuarias establece que son prestaciones patrimoniales de carácter público y naturaleza tributaria con independencia de que el servicio se preste directa o indirectamente. Ello supone para algunos autores (Ruiz Garijo 2008) que el concepto de tarifa tenga los días contados, lo que no debiera perderse de vista en la financiación de cualquier infraestructura. No obstante, a estos efectos hay que matizar que desde nuestro punto de vista no todos los precios se ven afectados por esta situación sino sólo aquellos en los que la recepción o utilización del bien o servicio es coactiva para el usuario, por lo que habrá de tener en cuenta si estamos o no ante un servicio esencial y si existen más alternativas para su recepción.

Todas estas figuras, de carácter tributario o no, permiten recuperar el coste de la inversión y tienen ventajas desde el punto de vista de la equidad, si bien es cierto que también pueden provocar desajustes desde esta misma perspectiva dependiendo de cual sea el tipo de servicio u obra al que se apliquen. En efecto, estas obras y servicios generan también un beneficio a la colectividad, y por consiguiente, si el servicio es esencial no parecería muy razonable que lo financie el usuario, por lo que es importante observar su utilización teniendo presente la política de gasto que se realiza, en tanto que sólo de esta manera se puede valorar la justicia del sistema.

b) La potencialidad de las contribuciones especiales en la financiación de obras públicas

Especial mención merecen las contribuciones especiales en la financiación de obras públicas, sobre todo en el ámbito local en donde tienen más posibilidades de aplicación. La Ley General Tributaria define este tributo en su artículo 2.2.b), que establece que son "...los tributos cuyo hecho imponible consiste en al obtención por el obligado tributario de un beneficio o de un aumento de valor de sus bienes, como consecuencia de la realización de obras públicas o del establecimiento o 
ampliación de los servicios". Estamos ante un tributo sometido a debate respecto a su conveniencia y que goza de ventajas como son: la inmediatez en relación con la realización del gasto público, un mejor ajuste gastoingreso y la posibilidad de reducir las desviaciones de poder que pudieran producirse en situaciones determinadas; ahora bien, su complejidad administrativa, las dificultades que ofrece la medición de la capacidad económica en muchos supuestos, así como la cuantificación por separado del beneficio individual y general han sido sus mayores desventajas (Calvo Ortega 2008).

Por ello hay que definir su régimen jurídico y observar su escasa utilización por el rechazo que los ciudadanos suelen oponer a su pago en un momento de desarrollo local avanzado, sobre todo, porque cada vez en mayor medida es más difícil valorar el beneficio o el aumento de valor que un sujeto experimenta en sus bienes por la realización de una obra o el establecimiento o ampliación de un servicio. En este sentido, el beneficio especial o aumento en el valor de los bienes se mide dependiendo del coste de la obra o servicio, separándose del esquema más ortodoxo en el ámbito tributario, en tanto que en estos casos es difícil medir el mercado porque no hay juego de mercado.

Ahora bien, es indudable que en determinados sectores en los que este acotamiento resulta más factible puede ser una figura con un importante potencial, y que además tiene una ventaja en relación con otras figuras, y es que su pago puede anticiparse, sin que haya que esperar a la efectiva prestación del servicio, por lo que permite generar crédito a medida que se va realizando la obra. Además son ingresos afectados en el ámbito local, siendo precisamente esta característica de la finalidad financiera de este tributo.

c) Las "tarifas" por prestación de servicios: exigencias constitucionales, y su ubicación en el concepto de tasa

Retomando la cuestión abierta en líneas precedentes en relación con las exigencias que el Tribunal Constitucional (en adelante, TC) ha impuesto a las tarifas, hay que señalar que en la generalidad de los supuestos, las normas, los convenios, contratos y pliegos de condiciones mediante los que se encomienda o atribuye la realización de una obra o la prestación de un servicio a la iniciativa privada venían calificando el precio como un precio privado, conteniendo en su caso la correspondiente tarifa. 

público-privada en la financiación de obras y servicios públicos en España

Como ha venido reconociendo el ordenamiento y la jurisprudencia, se trata de una forma de intervención reguladora de las condiciones económicas de la prestación del servicio público que es manifestación de la potestad tarifaria de las administraciones públicas distinta de la tributaria. Esta ha sido la forma tradicional de fijar la financiación de los concesionarios ya que la tarifa posibilitaba obviar muchas de las dificultades que presentan las tasas. Entre otras ventajas podían prever una cuantificación de pagos que cubriera el coste del servicio y que arrojaran un razonable beneficio para el concesionario.

Ahora bien, como consecuencia de los mencionados pronunciamientos del TC relacionados con esta materia (SSTC 102,121 y $122 / 2005)$, cuando el servicio prestado sea coactivo y persiga un fin público, estamos ante una prestación patrimonial de carácter público, afectada por la reserva de ley, y según defiende un sector doctrinal (Cayón Galiardo y Almudí Cid 2008) hay que reconducir la contraprestación a la categoría tributaria de tasa, ya que la expresión: "en régimen de derecho público", que utiliza su actual definición en la Ley 8/2003, General Tributaria (en adelante, LGT), se refiere a cualquier servicio cuya titularidad corresponda a un Ente público con independencia de la modalidad mediante la que se gestione, pudiendo incluso llegar a afectar los supuestos en los que aun prestándose el servicio conforme a las normas jurídico-privadas, se le restringe el derecho o anula la competencia.

Esta consideración de tasa provoca algunos problemas a la hora de articular, por ejemplo, la retribución del concesionario en tanto que es difícil armonizar el concepto de tasa con el derecho del gestor privado a obtener beneficios empresariales, ya que aunque pudieran incluirse esos beneficios en el coste del servicio no parece razonable que éstos deban ser sufragados por los beneficiarios del servicio, sobre todo cuando se trata de servicios que cubren necesidades básicas demandadas por sectores de menor capacidad económica. También resulta complejo introducir el régimen jurídico de la tasa con su recaudación por el concesionario -para lo que algunos autores han propuesto la figura del sustituto del contribuyente-, o con el equilibrio económico financiero de la prestación.

En este sentido, coincidimos con la doctrina de referencia cuando señalan que lo más oportuno hubiera sido calificar las obligaciones pecuniarias por la recepción de estos servicios como prestaciones patrimoniales de carácter público, sometidas al principio de reserva de 
ley pero no al régimen jurídico de las obligaciones tributarias (Cayón Galiardo y Almudí Cid 2008).

En definitiva, todas estas consideraciones tienen que tenerse en cuenta en el momento de optar por la exigencia de una de estas modalidades de financiación de las obras públicas, y al respecto compartimos la idea de que tanto las características de la infraestructura, como la presencia de una finalidad pública y la situación de infraestructuras alternativas (Juan Lozano y Rodríguez Márquez 2006), serán las que determinen la necesidad de someter su exacción al principio de reserva de ley, e incluso, estos criterios debieran servir para establecer un planteamiento general de los recursos con los que puede financiarse la provisión de bienes y servicios a los ciudadanos.

En esta línea, entendemos que los bienes y servicios que se consideran esenciales han de financiarse con cargo preferiblemente a impuestos, el resto de servicios que no tengan esta característica -por si misma variable- podrán financiarse o costearse por quienes se benefician de su establecimiento o prestación. En el caso que sea coactiva su exigencia, deberá de sujetarse al principio de reserva de Ley, en otro caso, en función de su carácter o no tributario, podrán dar lugar a la exigencia de una tasa o contribución especial, si se gestiona por la Administración, o de una tarifa, si el servicio se gestiona indirectamente por el sector privado.

C. La colaboración público-privada como alternativa de financiación de obras y servicios públicos

Ante la insuficiencia de recursos públicos para hacer frente a las demandas de obras públicas y de prestación de servicios, la utilización de determinadas fórmulas para la participación del sector privado en la financiación de obras públicas se perfila como una alternativa para poder seguir acometiendo inversiones de estas características.

Con carácter previo es preciso diferenciar estas vías alternativas de financiación privada respecto de otras fórmulas en las que el sector privado financia (entidades financieras o directamente ahorro privado) pero sin asumir el riesgo inherente a la prestación de fondos al sector público para desarrollar obras públicas. Precisamente éste es el elemento que diferencia y caracteriza estas fórmulas de financiación.

A su vez dentro de los mecanismos de colaboración público privada, es posible diferenciar los mecanismos en los que ese riesgo es compartido por los sectores público y privado, y aquellas en las que el 
sector público establece las condiciones de prestación y la financiación privada asume el riesgo y la producción del servicio en exclusiva. Asimismo, en tanto que muchos de estos proyectos públicos de inversión no son atractivos inicialmente para el sector privado o generan muchas incertidumbres por los riesgos que debe asumir, y sin embargo son deseables desde el punto de vista económico y social, en ocasiones la Administración se ve obligada a incrementar su atractivo haciéndoles más rentables (subvenciones a la inversión o a la explotación, anticipos reintegrables, avales, aportaciones de capital, aportación de terrenos, etc.), o bien a limitar los riesgos del proyecto de forma que se incremente el interés por la realización de estos proyectos, abriendo la puerta a mecanismos que persiguen más el diferimiento del pago de la inversión por parte de la Administración que otros objetivos. Paralelamente, una premisa imprescindible para el desarrollo de estas fórmulas de financiación es un marco normativo estable y adecuado, que permita su desarrollo con la mayor seguridad jurídica.

Ahora bien, a pesar del importante protagonismo del sector privado en este ámbito, las administraciones públicas siempre tendrán que estar presentes en estos proyectos de financiación en tanto que son garantes del interés general, y en último término, la Administración mantiene la titularidad del servicio, una capacidad de decisión relevante y un control sobre las condiciones con las que se presta el servicio, e incluso deberá de garantizar que éste se realiza cuantitativa y cualitativamente en condiciones adecuadas.

a) Delimitación del concepto de colaboración público-privada

Cuando se alude a la financiación privada de infraestructuras públicas se hace referencia a diversas situaciones y fórmulas de financiación con participación del sector privado que hemos tratado de delimitar al principio de este estudio. No obstante, a pesar de esa aproximación inicial, no existe un concepto de colaboración público-privada por lo que para aproximarnos al mismo nos basamos en las consideraciones que el Libro Verde sobre la colaboración público-privada y el Derecho comunitario en materia de contratación pública y concesiones ha realizado al respecto señalando que "la CPP designa una forma de cooperación entre las autoridades públicas y los agentes económicos. Esta cooperación tiene por objeto, en particular, financiar, construir, renovar o explotar una infraestructura o el suministro de un servicio" (Comisión Europea 2004). 
Esta descripción de las fórmulas de CPP admite múltiples posibilidades, existiendo cierto consenso en que sus elementos definitorios, además de la asunción de riesgos por la iniciativa privada, son: una duración relativamente larga; un método determinado de financiación y un relevante papel del operador privado. A pesar de contar con estos elementos comunes, es evidente que los perfiles de la CPP no están definidos, lo que entendemos que viene motivado porque es un concepto en constante evolución que se va adaptando a lo que las necesidades de los Estados demandan, un concepto de difícil delimitación al que sólo se puede realizar una aproximación a través de sus rasgos definitorios, rasgos que desde nuestro punto de vista también están en constante evolución.

Por lo que respecta a la duración de la relación que se establece en la colaboración, se trata de fórmulas que suelen tener una vigencia superior a veinte años, aunque encontramos ejemplos de obras públicas de varias décadas de duración. Un ejemplo lo encontramos en la construcción y explotación del viaducto de Millau, realizado sobre el esquema concesional y cuya duración propuesta por el adjudicatario fue de setenta y cinco años. Este aspecto está íntimamente relacionado con la equidad, de manera que si el objeto de la colaboración es una larga vida útil parece razonable que no se financie exclusivamente a cargo de presupuestos actuales sino que su coste se difiera a lo largo de ésta.

En relación con el modelo de financiación ya se ha aludido a que estas fórmulas suelen apartarse de la tradicional financiación con cargo a los presupuestos.

Si se piensa en el reparto de riesgos, éstos deben ser compartidos entre la Administración y el socio privado, si bien es cierto que desde nuestro punto de vista se ha ido evolucionando hacia fórmulas -tanto las modificaciones del contrato de concesión de obra pública como el contrato de colaboración entre el sector público y el sector privado, son una prueba de ello-, en las que este componente de asunción de riesgo se va suavizando y la remuneración del operador privado se vincula a estándares de calidad y disponibilidad que han ido relajando esta nota delimitadora de las fórmulas de CPP y que nos lleva a pensar de nuevo que el eje de la utilización de estos mecanismos pivota sobre el diferimiento de la inversiones a presupuestos futuros y no tanto sobre su repercusión sobre el déficit y el endeudamiento de las administraciones, y todo ello, sin perjuicio de que este último aspecto no debiera nunca descuidarse por las consideraciones realizadas al principio de este trabajo. Al igual que no debiera relegarse la importancia que la utilización de la CPP puede tener 
en la utilización de técnicas más eficientes de gestión de los servicios a las que también se ha hecho ya referencia. Precisamente, en el siguiente epígrafe se pretende profundizar un poco más en estos aspectos.

b) Justificación y objetivos de la colaboración públicoprivada en la financiación de obras y servicios públicos

En este momento de la exposición, ha sido inevitable haber adelantado la justificación y los objetivos de las fórmulas de CPP, pero es conveniente poner de manifiesto que al igual que van modificándose y complicándose las fórmulas de colaboración utilizadas, los objetivos y justificación de su utilización también van variando y provocan que las Administraciones vuelvan a forzar los límites de los contratos administrativos típicos para dar cobertura a nuevas necesidades de realización de obra pública. Uno de los ejemplos más claros de esta situación es la actual regulación del contrato de colaboración público privada que da la posibilidad de realizar obra pública con colaboración público-privada cuando el servicio al que está afecta no es susceptible de explotación.

La utilización de estas fórmulas en nuestro país posiblemente comenzó buscando flexibilidad en la gestión, posteriormente se dio un paso más tratando de soslayar las limitaciones del déficit y del endeudamiento presupuestario en un escenario económico favorable y con un sector privado económicamente fuerte, y por último, ha evolucionado hacia planteamientos en los que se tratan de superar las estrecheces presupuestarias de nuestras Administraciones en un momento en el que la inversión en infraestructuras es clave para nuestra recuperación económica y mejora de nuestra competitividad, por lo que un objetivo importante es producir un diferimiento del gasto a presupuestos futuros.

No obstante, conviene recordar que desde los planteamientos de quienes defienden la utilización de estas fórmulas de colaboración, el objetivo prioritario de su utilización debe ser aprovechar los conocimientos y métodos del sector privado para aplicarlos al ámbito de lo público debido a la capacidad de la empresa de rentabilizar las inversiones y porque el desarrollo de estas fórmulas forma parte de la evolución más general del papel del Estado en el ámbito económico, al pasar progresivamente de ser operador directo a organizador regulador y controlador.

Por otro lado, parece razonable sacar de la Administración actividades que pueden estar orientadas al mercado, dejando los recursos públicos para financiar otras menos proclives al mismo. 
Por consiguiente, el objetivo debiera de ser la búsqueda de modelos óptimos que garanticen la eficiencia de los recursos invertidos y de la gestión de los servicios prestados con la obra pública ejecutada. De otro modo, sólo estaríamos ante fórmulas de contabilidad creativa, y por tanto, de modelos instrumentales que llevarían a su consolidación de las cuentas de la Administración promotora en cuanto se revisaran los criterios de contabilidad nacional.

En la medida que estas figuras se utilicen con la finalidad de potenciar la racionalización del gasto público y la introducción de criterios de eficiencia, eficacia, economía y calidad en la prestación de los servicios públicos vinculados a las obras públicas que se financian con colaboración privada, estará más justificada su existencia desde la perspectiva de los principios materiales que informan el gasto público.

Retomando las limitaciones que impone el cumplimiento de los criterios de estabilidad, no debe olvidarse que el impulso definitivo de estas fórmulas en nuestro país desde hace seis años se produce por las restricciones del déficit y el endeudamiento público a las que se ha hecho referencia.

No obstante, no puede obviarse que la utilización de muchas de ellas permite diferir el pago de las inversiones, y por consiguiente, en los momentos actuales aunque la CPP no es una solución milagrosa su utilización posibilitará a las Administraciones seguir invirtiendo en una situación de fuertes reducciones presupuestarias y de un horizonte de reconducción de los déficits acumulados por los Estados en estos últimos años.

c) La colaboración público-privada en la financiación de obras y servicios públicos en España

1. Principales vías de financiación público-privada utilizadas en España y su encaje en la regulación vigente

En este epígrafe se trata de recordar de forma sistematizada cuáles son las fórmulas de financiación que se han venido utilizando en nuestro país, en qué momentos, cuál ha sido su justificación, cuál es la normativa que ha amparado su aplicación y, de existir, cuales son sus especialidades o características más relevantes de su régimen jurídico.

Así, la creación de sociedades mercantiles participadas mayoritariamente o totalmente por la Administración que va a acometer 
la ejecución y gestión de la obra, ha sido de utilización recurrente en nuestro país por lo que recibió el nombre de "modelo español".

Con carácter general se trata de entidades instrumentales que actúan por cuenta de la Administración matriz y que tienen capacidad de endeudamiento.

Hasta hace unos años posibilitaban escapar a las restricciones de la estabilidad presupuestaria en tanto que su endeudamiento no se consideraba endeudamiento del ente público, aunque tras la entrada en vigor de las normas SEC-95, esta fórmula ha perdido en algunos casos parte de su aliciente en tanto que Euroestat ha previsto su tratamiento en la contabilidad nacional -existiendo la posibilidad de que su deuda compute a efectos de estabilidad presupuestaria-, distinguiendo entre administraciones públicas y empresas según un estricto criterio de mercado y con independencia de la titularidad pública o privada de la sociedad. De este modo, si el operador económico vende su producción en el mercado debe integrarse en el sector empresas y su endeudamiento no computa. A su vez, se considera que orienta su producción al mercado cuando sus ingresos por ventas cubren al menos el 50 por 100 de los costes totales de explotación y a estos efectos los pagos de la Administración matriz no tienen la consideración de ventas.

Con este nuevo escenario muchas sociedades han pasado a computarse como Administración Pública, y por consiguiente, su endeudamiento computa, por lo que algunas han optado por utilizar alguna variante en su modo de financiarse, como por ejemplo titulizando los derechos de crédito que le genera el compromiso de la Administración matriz de realizar transferencias a su favor para afrontar el pago de la obra pública, lo cual le permite descontar estos activos anticipadamente y cancelar deuda. No obstante, en estos casos el riesgo de la operación se traslada a la Administración matriz.

En relación con la creación de entidades de estas características, hay que tener presente operaciones en las que un gestor privado adquiere el control de una entidad pública, y adquiere carácter comercial obteniendo la mayor parte de sus ingresos en el mercado. En estos casos se diferencia del denominado "modelo español" en tanto que sus ingresos proceden mayoritariamente de su actividad y tiene su propia capacidad de endeudamiento. Admiten también capital privado sin que sus ingresos dependan de los compromisos públicos. 
Por lo que respecta al contrato de obra en su modalidad de pago diferido también se regula inicialmente por la mencionada ley de medidas fiscales y que todavía no ha sido derogado, aunque en la actualidad este tipo de contrato se encuentra incluido en el artículo 99.2 del LCSP, tal y como ha sido interpretado por la Ley $47 / 2003$, de 26 de noviembre, General Presupuestaria (LGP). Se previó como un mecanismo excepcional ideado exclusivamente para la construcción inicial de determinadas obras públicas y siempre que su precio de licitación no superara determinados umbrales. La aplicación de esta medida ha sido intermitente. Se ha utilizado en el ámbito estatal, aunque en tanto que compromete presupuestos futuros se ha establecido un límite al volumen de inversión que puede contratarse por esta modalidad. En el ámbito autonómico se puso en duda su aplicabilidad, aunque muchas CC.AA. regularon expresamente la aplicación en su ámbito competencial de la normativa estatal precitada.

En este supuesto sólo se exige un certificado de compromiso de gastos futuros -no de existencia de crédito-. No existe la posibilidad de declarar nulo el contrato por inexistencia de crédito. En estos casos se excepciona la regla general que prohíbe el pago aplazado de los contratos para los contratos de las administraciones públicas. Debe incorporar un informe del Ministerio de Economía y Hacienda u órgano equivalente de la Administración competente. El ejercicio presupuestario en el que se recepcione la obra, el crédito para hacer frente al compromiso de gasto debe consignarse con carácter preferente. Existe la posibilidad de que si la obra es susceptible de explotación, la Administración opte porque todos o parte de los pagos previstos se financien mediante el cobro de un peaje o tasa por el uso de la infraestructura, supuestos en los que esta fórmula tendría menos incidencia en el presupuesto, evitándose una de sus mayores críticas que es la de que este mecanismo compromete presupuestos futuros por los que ha de limitarse su utilización.

De cualquier forma, esta modalidad ha perdido parte de su atractivo tras la entrada en vigor del SEC-95 porque la posibilidad de fraccionar el pago en diez años que permitía periodificar su incidencia en el déficit se ha modificado en tanto que éste se computa en el momento de la recepción de la obra.

Por lo que se refiere al contrato de concesión de obra pública han existido múltiples precedentes en normas sectoriales que se basaban en este tipo de contratos para ámbitos específicos. En este sentido fue pionera y avanzada la Ley 8/1972, de 10 de mayo, sobre construcción, conservación y explotación de las autopistas de peaje en régimen de 
concesión. En este marco, también fue un hito relevante la mencionada Ley 13/1996 que introdujo el régimen jurídico del contrato de construcción y explotación de obras hidráulicas.

En España, en el ámbito estatal, salvo algún precedente lejano similar a esta técnica, hay constancia de que se trató de incorporar en la Ley 13/1996, aunque finalmente no se incluyó. Sin embargo, en el ámbito autonómico, algunas comunidades, Madrid, Murcia y la Comunidad Foral de Navarra, incorporaron esta técnica con distinta amplitud.

La aprobación de la Ley 13/2003, de 23 de mayo, reguladora del contrato de concesión de obra pública, es la norma que ha abierto la figura de la concesión de obra pública como una vía prioritaria de colaboración público privada en la ejecución de estas infraestructuras, esto es dio carta a la colaboración público-privada en su forma no institucionalizada y abrió la posibilidad de uso de estas fórmulas por las Administraciones hasta el límite de desdibujar sus contornos.

En estos casos, Euroestat ha aplicado criterios específicos para su contabilización reconduciéndolos contablemente a su consideración como un arrendamiento operativo o financiero. En España parece que gran parte de los modelos se reconducen al supuesto de arrendamiento financiero. A efectos de computo de deuda no será tenida en consideración si el riesgo de la construcción y el riesgo de disponibilidad o de demanda son soportadas por la parte privada, con independencia de que existan pagos por parte del ente público al socio privado.

Precisamente, como ya hemos adelantado, puso de manifiesto la necesidad de crear figuras más flexibles que posibilitaran salir al paso de la escasez de recursos presupuestarios de las Administraciones y en este ámbito adquiere gran relevancia el nuevo contrato de colaboración pública entre el sector público y privado, que se inspira en la regulación francesa y británica de esta fórmula de CPP (Jiménez Díaz 2009).

Hasta aquí se ha aludido a las modalidades que se han utilizado y se vienen aplicando en España, si bien hay que concluir que aunque las posibilidades de financiación público-privada se han reconducido hasta fechas recientes al contrato de concesión de obra pública, nuestro mayor interés reside en realizar una aproximación a los caracteres del contrato de colaboración del sector público y privado que se contempla en la LCSP, ya que como acaba de exponerse abre un abanico de nuevas posibilidades en la que tienen cabida fórmulas muy complejas siempre 
que se ajusten a los requerimientos que establece la normativa vigente y que pasan a exponerse.

2. Nuevas perspectivas de financiación mediante el contrato de colaboración entre el sector público y privado

En el artículo 11 de la LCSP se regula un nuevo modelo contractual el "Contrato de colaboración entre el sector público y el privado", contrato que se caracteriza porque abarca actuaciones de caracteres muy dispares en los que la idea de complejidad está muy latente. Esta regulación deja muy abierto el objeto del contrato para facilitar cualquier tipo de prestación por parte del contratista, por lo que no puede dejar de subrayarse la flexibilidad que ofrece para diseñar diversas alternativas de CPP, y que posibilita la utilización de figuras que tenían difícil encaje en los contratos nominados previstos en la anterior regulación, como los arrendamientos operativos, que se habían venido celebrando utilizando el margen que posibilitaba la legislación de régimen patrimonial de las administraciones públicas.

Ya hemos expuesto con anterioridad cuál es la definición legal de este contrato, de donde se desprende que el legislador ha pretendido que en la misma encajaran todos los objetos contractuales existentes -contrato de obras, con gestión de servicios públicos, de concesión de obra pública, de de suministro y del de gestión de obra pública-, lo que supone que se trata de una forma de contratación subsidiaria que sólo puede utilizarse cuando el objeto perseguido no pueda obtenerse a través de la licitación de otro contrato.

Además de la subsidiariedad, la complejidad, la transferencia de riesgos, la eficiencia y la economía están latentes en la regulación de este contrato (artículos 11 y 118 de la LCSP).

Esta regulación recoge también la necesidad de que la Administración contratante realice una "evaluación previa" que puede compararse al trámite desarrollado en otros países consistente en valorar en términos económicos si compensa o no la celebración de un contrato con CPP, lo que inicialmente es una garantía de eficiencia en el sentido de que con este instrumento se persigue ponderar los costes y riesgos que pueden generarse durante la vida de un proyecto, comparando los que previsiblemente se producirían si el proyecto fuera realizado por la Administración. En definitiva se trata de valorar si la participación en esta forma de iniciativa privada resulta más oportuna, a pesar del mayor 
coste que probablemente conllevará en relación con otras alternativas. Precisamente el artículo 118 de la LCSP bajo la denominación de "evaluación previa" contiene algunas de las notas que caracterizan este contrato al señalar que:

... la Administración deberá elaborar un documento de
evaluación en que se ponga de manifiesto que, habida
cuenta de la complejidad del contrato, la Administración
no está en condiciones de definir, con carácter previo a
la licitación, los medios técnicos necesarios para
alcanzar los objetivos proyectados o de establecer los
mecanismos jurídicos y financieros para llevar a cabo el
contrato, y se efectúe un análisis comparativo con
formas alternativas de contratación que justifiquen en
términos de obtención de mayor valor por precio, de
coste global, de eficacia o de imputación de riesgos, los
motivos de carácter jurídico, económico, administrativo
y financiero que recomienden la adopción de esta
fórmula de contratación.

Otra de las novedades es que con carácter general se limita la duración de los proyectos a 20 años, aunque cuando el objeto del contrato se corresponda con las prestaciones propias del de concesión de obra pública puede tener una vida de hasta 40 años, o incluso 75 cuando se trata de obras hidráulicas.

Por otra parte, el contratista adjudicatario va a recuperar el coste de la inversión realizada mediante un "...precio que se satisfará durante toda la duración del contrato" (artículo 11.4 LCSP), sin que se prevea otra forma de retribución. Frente a esta opción la concesión de obras públicas permite optar entre varias soluciones para retribuir al concesionario, fórmulas que van desde el cobro de tarifas a los ciudadanos a las fórmulas de "peaje en sombra" muy cercanas a la retribución de este contrato.

En definitiva, como ha señalado la doctrina (Jiménez Díaz 2008), con esta figura las administraciones públicas pueden incorporar a la gestión pública las técnicas del sector privado y desde luego, obtener de éste financiación para nuevos proyectos que, además de complejos, supongan inversiones cuantiosas a las que las Administraciones no podrían acudir sin incurrir en déficits insostenibles. Ante esta situación, el contrato de colaboración también constituye una solución financiera que, además, podría superar con éxito el examen de las instituciones europeas en la medida que se ajuste a los criterios de EUROSTAT de transferencia de riesgos. 
IV. LAS FÓRMULAS DE COLABORACIÓN PÚBLICO-PRIVADA A LA LUZ DE LOS PRINCIPIOS QUE INFORMAN EL GASTO PÚBLICO Y SU CONFIGURACIÓN Y PROGRAMACIÓN EN EL PRESUPUESTO

A. Análisis de las fórmulas de financiación con colaboración público-privada a la luz de los principios constitucionales que informan el gasto público

El artículo 31.2 de la Constitución Española señala que el gasto público realizará una asignación equitativa de los recursos públicos y su programación y ejecución responderá a los principios de eficiencia y economía. A su vez, el artículo 133.4 del texto constitucional recoge el que podría denominarse: principio de reserva de ley en el gasto público.

Por este motivo, es preciso recordar el significado de estos principios, que en definitiva son controles a los que la CE somete a las decisiones de gasto, para ver en que medida las fórmulas de colaboración público-privada a las que se ha hecho referencia se adecuan a los mismos.

a) Principios materiales: equidad, eficiencia y economía

La doctrina (Albiñana García-Quintana 1979) atribuye verdadero valor normativo a los principios materiales de justicia consagrados en el artículo 31.2 que establece que "el gasto público realizará una asignación equitativa de los recursos públicos y su programación y ejecución responderán a los criterios de eficiencia y economía". Son de todos conocidas las dificultades que implica establecer los mecanismos a través de los que hacer efectivos estos principios, dificultad que se incrementa cuando se trata además de decidir si la utilización de fórmulas de CPP en la financiación de obras y servicios públicos son respetuosos con los mismos.

A pesar de las dificultades, la reflexión sobre la influencia de los principios materiales de justicia del gasto público en el análisis de las fórmulas de financiación de obras públicas con la colaboración del sector privado reviste gran importancia, y desde nuestra perspectiva su enjuiciamiento debe poner de manifiesto la necesidad de un mayor desarrollo del Derecho de los gastos públicos (Bayona de Perogordo 1982), superando, una visión de los mismos apegada a la institución presupuestaria. En efecto, desde esta última perspectiva la utilización de estas fórmulas es respetuosa en términos generales con las exigencias constitucionales y legales que implican estos principios, pero por sus repercusión en las 
decisiones de gasto y en los recursos con los que deben financiarse, cuestiones como: la elección de las fórmulas utilizadas para atender las necesidades públicas con cargo a recursos públicos o privados, o las repercusiones que pueden tener en los presupuestos futuros, deben ser decididas con sujeción a normas que disciplinen la naturaleza del gasto y sus aspectos materiales. En definitiva, exigen superar la interpretación de estos principios con una visión apegada al instituto del presupuesto y entender el gasto como algo más que una función pública atribuida legalmente a un ente público (García Novoa 2001).

La utilización de estas fórmulas demanda una decisión previa respecto de si resulta deseable sacar de la financiación tradicional, articulada a través del presupuesto, los gastos en inversión que pueden resultar atractivos para el gestor privado en tanto que son susceptibles de explotación y destinar los recursos presupuestarios para actividades menos proclives al mercado. Desde este enfoque parece que no hay obstáculo para adoptar esta decisión, sobre todo si se tiene en cuenta que la insuficiencia de recursos en otro caso puede conllevar la no realización de determinadas obras públicas.

Por lo que se refiere a la asignación equitativa de recursos públicos, este principio implica que se contemplen los recursos económicos suficientes para hacer frente a las necesidades públicas y estas necesidades parecen identificarse con las necesidades públicas constitucionales (García Novoa 2001), esto es, las configuradas como derechos constitucionales y las que atienden a los principios rectores de nuestra política social y económica de nuestra Carta Magna.

Por tanto, en una primera aproximación, esta exigencia constitucional sólo implica que el gasto público se destine a una de estas necesidades (educación, vivienda, infraestructuras de transporte, sanidad...). Ahora bien, entendemos que esta exigencia es muy débil y cualquier decisión de utilización de fórmulas de CPP en la financiación de infraestructuras públicas, debe tener en consideración otras exigencias que desde nuestro punto de vista demanda el principio de asignación equitativa de recursos públicos.

Profundizando más en las exigencias de este principio, consideramos que éstas deben proyectarse (Orón Moratal 1995) en tres momentos diferentes del gasto público: en primer lugar en el momento de la elección del recurso, en segundo término, en el momento de la autorización o empleo de recursos públicos, y finalmente, en el momento 
de la asignación de los gastos autorizados para la satisfacción de los fines públicos. Las dos primeras parecen afectar al poder legislativo, y la última a la Administración encargada de asignar los gastos autorizados a la satisfacción de las necesidades públicas.

En relación con el primero de los momentos en los que actúa este principio, esto es, en relación con el momento de la elección del recurso que debe utilizarse para satisfacer una determinada necesidad, ya se ha hecho referencia en líneas precedentes a la importancia que tiene este aspecto en la financiación de obras y servicios públicos, hasta el punto que los recursos pueden llegar a determinar la forma de acometer la obra o infraestructura pública. Por consiguiente, no se trata solamente de atender al aspecto cuantitativo del recurso, sino también al cualitativo (Cayón Galiardo 1988), y en esta medida este principio de equidad no sólo afecta al poder legislativo al establecer el crédito -aspecto cuantitativo- con el que se va a desarrollar una determinada inversión, sino también a la Administración que tiene que adoptar una decisión equitativa a la hora de decidir como se va a financiar una determinada infraestructura u obra pública.

Por lo que se refiere al momento de la autorización del empleo de recursos públicos para satisfacer necesidades públicas, nos encontramos con la particularidad de que la decisión de la Administración sobre el modelo de financiación de una obra pública y su posterior servicio puede conllevar discriminaciones de unas necesidades frente a otras, o desigualdades por la aplicación de distintos modelos de financiación dentro de una misma necesidad. Incluso, las decisiones de la Administración sobre el modelo de financiación, pueden no dejar claros los compromisos de gasto que se están asumiendo a largo plazo con cargo a presupuestos públicos. Todos estos casos, quedarían al margen de la decisión del legislativo tanto la priorización de las necesidades a satisfacer como el que no se produzcan discriminaciones en la selección de las necesidades.

Por lo que respecta a la verificación del principio de equidad en el momento de la asignación de los gastos autorizados hay que señalar que se trata de un mandato dirigido a la propia Administración, en tanto que la asignación por el legislativo de los créditos presupuestarios deja mucha libertad sobre el modo en el que debe realizarse el gasto, e incluso, modificar las previsiones de destino del gasto. Así podría vulnerar el principio de equidad que la elección del modo de financiar dos infraestructuras hospitalarias en una misma comunidad autónoma, una con cargo íntegramente a créditos presupuestarios y otra con colaboración 
del sector privado si en este último caso se modificara la calidad del servicio de los usuarios o conlleva la exigencia de pago a los usuarios. En el ámbito de las infraestructuras terrestres, por ejemplo, podría vulnerar este principio dentro del mismo ámbito territorial de una comunidad autónoma si éstas se realizaran con distintos modelos de financiación que en unos casos implicaran peajes y en otros fueran gratuitas. Estos ejemplos nos llevan a poner de manifiesto que este principio está muy vinculado con el principio de igualdad (Cazorla Prieto 1979) y con la vertiente territorial de este principio (Juan Lozano y Rodríguez Márquez 2006).

Lo expuesto hasta este momento se refiere a una fase inicial en la que se priorizan los gastos y se deciden dentro de cada ámbito competencial los recursos con los que se van a acometer, aunque también sería deseable tener presente la equidad y la adecuación de la decisión una vez acometido el proyecto, en una fase posterior de control, con el objetivo de detectar y corregir deficiencias, sobre todo en lo que respecta a la calidad de los servicios, con la finalidad de controlar que las obras y servicios públicos destinados a atender las necesidades de los ciudadanos, cuando en su financiación interviene el sector privado, cumplen los requisitos de calidad establecidos por el sector público y se ofrecen a unos precios razonables. Todo ello nos lleva a su vez a analizar la eficacia y la eficiencia en el acceso a estas infraestructuras y servicios.

Por lo que respecta a los principios de eficiencia y economía hay que recordar que el respeto a estos postulados responde a las tendencias seguidas en los países de la OCDE que buscan incentivar una gestión de recursos que valore la eficiencia en el gasto público. Precisamente, como sabemos, las fórmulas de CPP en la financiación de obras y servicios públicos se incardinan en esta tendencia. Nuestra legislación presupuestaria, concretamente la Ley General de Estabilidad Presupuestaria (en adelante LGEP) afirma que las políticas de gastos públicos deben orientarse a la eficacia, a la eficiencia y a la calidad, si bien esta afirmación queda limitada a la fase de ejecución del gasto público.

Pues bien, respecto del criterio de eficiencia, que mide la razón entre lo que se realiza y lo que podría realizarse, la CE establece la necesidad de conseguir la mejor proporción entre un elemento dado y otro alcanzable (Bayona de Perogordo 1991). Este principio exige que las necesidades públicas se tomen en cuenta y que traten de satisfacerse del mejor modo posible. El principio de economía, por su parte, exige que se obtenga la máxima satisfacción de los recursos escasos de los que se dispone. Por consiguiente, estos principios exigen que antes de elegir el 
modelo de financiación para acometer las obras públicas se analice cuál es el más adecuado dentro de las opciones existentes, de manera que con los recursos disponibles se alcance la máxima satisfacción, aunque con los límites que imponen los distintos aspectos de la asignación equitativa de recursos públicos.

Bajo este punto de vista, la utilización de financiación del sector privado, en la medida que permite que las obras más rentables se orienten a la financiación privada, quedando el presupuesto para articular las infraestructuras públicas menos atractivas para el inversor privado, encaja con los postulados de estos principios, en tanto que la consecución de los mismos ha de observarse globalmente y no para cada una de las decisiones de gasto.

Además, las técnicas incorporadas recientemente en la LCSP, concretamente en la regulación del contrato de colaboración entre el sector público y el sector privado, semejantes a las que se venían utilizando en otros países y con las que se trata de valorar la eficiencia del gasto público, fomentan una cultura con más conciencia de coste y preocupación por la productividad y calidad en la provisión de bienes y servicios públicos, por lo que son acordes con los mencionados criterios constitucionales.

Por otra parte, las disposiciones relativas al control del gasto recogidas en la Ley General Presupuestaria, esto es la auditoría operativa en sus tres modalidades: programas presupuestarios, de sistemas y procedimientos, y de economía, eficacia y eficiencia, tienen mayor eficacia jurídica aunque su principal inconveniente para asegurar el cumplimiento de estos principios en la realización de inversiones públicas es que sólo se refieren a la fase aplicativa del gasto público sin que incidan sobre la selección de necesidades. Por tanto, sólo constituyen un control a posteriori que impide corregir las deficiencias del ejercicio presente (Juan Lozano y Rodríguez Márquez 2006).

b) Principios formales: la reserva de ley en el gasto público

El artículo 133.4 de la CE establece que "las administraciones públicas sólo podrán contraer obligaciones financieras y realizar gasto de acuerdo con las leyes". Según un sector doctrinal (Bayona de Perogordo 1991) este precepto no se identifica sin más con el principio de legalidad presupuestaria sino que implica que la ley sea el vehículo para disciplinar el gasto público, sin que se limite a establecer la sujeción de la 
Administración al principio de legalidad en su gestión. Si esto fuera así, sería la ley la que debiera contener el régimen jurídico del gasto público, tanto en lo afectante a las decisiones de gasto como a los procedimientos de gestión y control, y las necesarias leyes de gasto, serían el lugar en el que deberían adoptarse la planificación de las inversiones en obras públicas, su temporalidad y las vías para su financiación, ya que de este modo dentro de los objetivos y limitaciones de la estabilidad presupuestaria sería más fácil adoptar decisiones de gasto dentro de los distintos ámbitos competenciales, que permitieran una asignación equitativa de recursos públicos sin que comprometieran los ingresos ni los gastos de ejercicios futuros.

No obstante, las decisiones a las que acabamos de aludir en líneas precedentes no deberían adoptarse sin el apoyo de una norma con rango de ley, porque en la ejecución del presupuesto la Administración puede estar comprometiendo de manera relevante presupuestos futuros y en esta medida afecta al principio estricto de legalidad- más allá de los límites de la plurianualidad sin habilitación legal para ello. Esto supone que las decisiones de gasto en obras públicas y su financiación debieran articularse en leyes que tuvieran presente tanto la perspectiva del ingreso como la del gasto, posibilitando una asignación equitativa de recursos públicos, eficiente y con la mejor relación de objetivos y recursos disponibles, limitando la actual discrecionalidad de la que dispone la Administración para decidir el destino de los créditos aprobados por el presupuesto, cuando son decisiones que pueden comprometer la distribución de gasto de ejercicios posteriores de manera relevante.

B. Aspectos presupuestarios de las fórmulas de colaboración público-privada en la financiación de obras y servicios públicos

Corresponde en este momento analizar todos los aspectos con incidencia en el marco presupuestario de las fórmulas de colaboración público-privada en la financiación de obras y servicios públicos, tanto en lo que afecta a su repercusión sobre el documento presupuestario como su análisis desde la perspectiva de los principios que informan la configuración del presupuesto, así como su programación, y fundamentalmente, desde la perspectiva del escenario presupuestario en el que ésta ha de realizarse. 
a) Incidencia presupuestaria de las fórmulas de colaboración público-privada en la financiación de obras y servicios públicos

Han sido muchos los criterios que se han utilizado para hacer referencia a la incidencia de las fórmulas de CPP en el presupuesto, destacando entre ellas las que tratan de sistematizarlas en función de su naturaleza presupuestaria o extrapresupuestaria, clasificación que parte de si la financiación de la obra pública acaba realizándose o no por los contribuyentes, con cargo por lo tanto a recursos públicos.

Ahora bien, las variantes que presentan las diversas fórmulas de CPP son tan diversas que es difícil encajarlas en una clasificación previa y el resultado es que hay más excepciones que los supuestos de CPP que encajan en la clasificación previamente establecida.

Por otra parte, la utilización de las diversas fórmulas de CPP han variado en la última década y si bien a mediados de los noventa se utilizaron con profusión en España los denominados modelo español y el alemán, en la actualidad han quedado relegados por otras fórmulas que no sólo pretenden el diferimiento o el aplazamiento de pagos, sino que permiten obtener otro tipo de ventajas de la aplicación de técnicas y planteamientos del sector privado, buscando la eficiencia y la calidad de los modelos. En otro caso, como de hecho ha sucedido, cualquier variación de las normas de contabilidad nacional puede alterar su utilidad como vehículo para evitar el endeudamiento, y por tanto, propiciar su desaparición o modificación.

Para clasificar la incidencia de las fórmulas CPP sobre el presupuesto se ha optado por diferenciar entre las presupuestarias y las no presupuestarias, aunque dentro de las primeras casi todas ellas se reconducen al concepto de fórmulas de financiación que venimos denominando interpresupuestarias (Blasco Delgado 2008), en tanto que queremos prestar especial atención sobre el hecho que acaban afectando a varios presupuestos, normalmente más allá de los límites de la plurianualidad.

Entre las fórmulas de financiación presupuestaria hay que hacer alusión a las siguientes:

a) La financiación tradicional a través de contrato de obra pública con abono de certificaciones que se realiza a través del Capítulo VI del Presupuesto (inversiones reales). En la medida que puede pagarse en varias anualidades se convierte en financiación interpresupuestaria aunque no diferida. 

público-privada en la financiación de obras y servicios públicos en España

b) La modalidad de abono total del precio, se realiza con cargo al Capítulo VI del Presupuesto pero de forma aplazada. El pago, a la recepción de la obra puede aplazarse hasta en 10 anualidades. Se trata de financiación diferida y en este caso interpresupuestaria.

c) El peaje en sombra. Pagos realizados por la Administración al gestor privado a través del capítulo IV del presupuesto de gastos (transferencias corrientes), ya que estas cantidades se consideran subvenciones a los usuarios. No son gasto de capital sino gasto corriente. De nuevo se trata de un modelo interpresupuestario con financiación diferida.

d) Gestión del proceso inversor por un ente público o privado al que se le transfieren los fondos. En estos casos la financiación se realiza con cargo al capítulo VII del presupuesto de gastos (transferencias de capital). Se tratará de un modelo interpresupuestario en la medida que las transferencias afecten a varios presupuestos. Dentro de estas fórmulas figuran también las sociedades instrumentales públicas que reciben ingresos con cargo a la Administración pública correspondiente. En estos casos, la financiación puede calificarse de interpresupuestaria en tanto que afectará a varios presupuestos.

e) Aportaciones a entidades que desarrollen actividades empresariales a través del capítulo VIII del presupuesto de gasto (variación de activos), fuera del presupuesto no financiero, y por tanto del déficit, aunque sí que tiene una incidencia diferida sobre el déficit en la medida que es necesario emitir deuda pública para financiar estas aportaciones, y por consiguiente, habrá que hacer frente a sus intereses, por lo tanto se trata de un modelo interpresupuestario diferido.

f) Modelos concesionales con financiación de la Administración y de los usuarios. Los pagos de la Administración al concesionario pueden articularse de muchas formas en tanto que se prevén distintas modalidades. Pueden articularse, por ejemplo, a través del Capítulo IV de transferencias corrientes, o del capítulo VII del presupuesto como una transferencia de capital o también a través del capítulo VIII, de variación de activos. Se trata en todos los supuestos de financiación interpresupuestaria y que en algunos casos conlleva el diferimiento de la deuda, como en este último supuesto por los motivos que se han expuesto. 
Por lo que respecta a las fórmulas no presupuestarias:

a) Cuando las entidades públicas no reciben asignación de los presupuestos, financiando su actividad por su propia actividad o mediante financiación ajena pero siempre con apoyo en la prestación de sus servicios. En la administración central cabe diferenciar entre entes públicos empresariales y sociedades estatales.

b) Concesiones puras, cuando el gestor privado recibe su retribución exclusivamente de los usuarios.

Por consiguiente, excepto estos dos últimos supuestos estamos ante fórmulas presupuestarias que afectan a varios ejercicios, por lo que se han calificado como interpresupuestarias, lo que nos lleva necesariamente al estudio de los principios configuradores del presupuesto, ya que éste en principio se basa en su anualidad y habrá que compatibilizarlo con estos gastos de carácter plurianual.

b) Análisis de las fórmulas de colaboración público-privada en la financiación de obras y servicios públicos desde la perspectiva de los principios presupuestarios

1. Principios configuradores del presupuesto

Finalmente, las fórmulas de CPP analizadas desde la perspectiva de los que se han denominado doctrinalmente principios configuradores del presupuesto y que se recogen en el artículo $134 \mathrm{CE}$. Estos principios son: el principio de competencia, el principio de universalidad, el principio de unidad y el principio de anualidad.

Desde la perspectiva del principio de competencia habrá que analizar en qué medida las decisiones de acometer determinadas obras públicas con fórmulas de CPP cuando la adopción de este sistema conlleva trasladar gastos a ejercicios presupuestarios futuros, y por tanto, comprometer su presupuesto, debiera de autorizarse expresamente por el legislador.

El principio de universalidad nos hace pensar si este principio se respeta cuando una fórmula de CPP prevé el desplazamiento temporal en la imputación presupuestaria de gastos realizados en el año, aunque este desplazamiento esté legalmente previsto. 

público-privada en la financiación de obras y servicios públicos en España

El principio de unidad demandará que todas las entidades del sector público estatal presenten sus presupuestos en unidad de acto, con independencia de su carácter de unidad de mercado desde el punto de vista contable.

El principio de anualidad que se refiere tanto a la aprobación como a la ejecución presupuestaria debe de compatibilizase con uno de los principios o reglas de la programación presupuestaria, como es la plurianualidad.

\section{Principios de programación y gestión presupuestaria}

Los principios de la programación presupuestaria son cuatro: la estabilidad presupuestaria, la plurianualidad, la transparencia y la eficiencia en la asignación y utilización de los recursos públicos, aunque los tres últimos están al servicio del primero que se analiza con más detenimiento en el siguiente epígrafe.

La regla de la plurianualidad no pretende ampliar la duración del ejercicio presupuestario sino el horizonte a la hora de establecer las previsiones presupuestarias. Estas previsiones, junto con los compromisos de gasto contenidos en cada política presupuestaria se vierten en los escenarios de previsión plurianual que elabora el Ministerio de Economía y Hacienda. Desde este punto de vista, en la medida que las fórmulas de CPP superan las previsiones de gastos plurianuales que con carácter general en nuestra legislación está limitada a cuatro años, vuelve a ponerse de manifiesto la necesidad de una norma legal que previera y autorizara los modelos de financiación de las infraestructuras públicas cuando utilizan modelos que difieren o aplazan el gasto con un horizonte temporal más amplio.

Por lo que se refiere al principio de transparencia, que es de naturaleza predominantemente contable, exige que los presupuestos y sus liquidaciones tengan información suficiente y adecuada para permitir verificar el principio de estabilidad presupuestaria. Por ello, la medición de los objetivos de estabilidad presupuestaria se debe realizar de conformidad con el Sistema Europeo de Cuentas Nacionales y Regionales, ya que la información posibilita su análisis y comparación. Este principio adquiere gran relevancia en el ámbito que se estudia en tanto que la transparencia demanda que los objetivos propuestos no enmascaren otros no confesados, que no se primen políticas territoriales o que no se establezca el verdadero coste de los objetivos propuestos. 
El principio de eficiencia en la asignación y utilización de los recursos públicos persigue una gestión de los recursos públicos orientada a la eficiencia, eficacia y calidad, aspecto que abre las puertas a determinados mecanismos de financiación con CPP que se justifican precisamente por la consecución de estos objetivos.

En relación con los principios de gestión presupuestaria hay que realizar una especial referencia al principio de no afectación de recursos en tanto en el ámbito de la financiación de obras públicas pueden ser constantes las excepciones que se plateen mediante el establecimiento de supuestos de gastos con financiación afectada.

c) Especial referencia al objetivo de estabilidad presupuestaria y su compatibilidad con las fórmulas de colaboración público-privada en la financiación de obras públicas

Uno de los motivos de la profusión de las fórmulas de colaboración público privada, tal y como se ha expuesto en un capítulo precedente es el escenario de limitaciones del déficit y del endeudamiento que ha provocado el objetivo de la estabilidad presupuestaria que nos llega desde Europa. En efecto, el principio comunitario de estabilidad presupuestaria recogido en el artículo 104.1 del TUE impide a los Estados incurrir en déficits excesivos, y se ha concretado en nuestro ordenamiento en la LGEP exigiendo que la elaboración, aprobación y ejecución de los presupuestos se realice en el marco de la estabilidad presupuestaria, de acuerdo con los principios derivados del Pacto de estabilidad y crecimiento. En este sentido, una primera tarea es definir qué ha de entenderse por estabilidad presupuestaria y sus exigencias en los distintos escenarios a los que afecta. Al respecto, hay que señalar que por estabilidad ha de entenderse la posición de equilibrio a la que en su caso se debe acceder a través de estrategias de saneamiento que eviten o disminuyan las pérdidas $y$ puedan aportar beneficios a su objeto social o institucional.

A su vez, es preciso señalar que debido a la interrelación existente entre la economía y las decisiones sobre ingresos y gastos, la presupuestación ha de realizarse con una perspectiva plurianual, que a nuestro juicio se perfila como el marco idóneo en el que deben adoptarse las decisiones referentes a la financiación de obras y servicios públicos y a las posibilidades de colaboración privada en este ámbito, ya que permitirá planificar las infraestructuras que hay que acometer, su repercusión sobre el conjunto de la economía, su financiación y su repercusión en presupuestos 
futuros, y en definitiva, permite asignar equitativamente recursos públicos escasos a las necesidades públicas más prioritarias, y decidir con una perspectiva más amplia que la anualidad presupuestaria la financiación de obras públicas.

Por ello se prevé unos escenarios plurianuales de programación presupuestaria como marco del proceso de asignación de recursos públicos que se definen como la programación de la actividad del sector público con presupuesto limitativo en los que se concretan los equilibrios presupuestarios básicos, la previsible evolución de los ingresos y los recursos a asignar a las políticas de gasto, en función de sus correspondientes objetivos estratégicos y los compromisos de gasto ya asumidos. Para hacer realidad estos escenarios plurianuales se han ampliado los compromisos de gasto de carácter plurianual, antes tasados, siempre que no superen las cuatro anualidades, salvo casos excepcionales.

Por otro lado, para poder verificar el cumplimiento de estos principios es necesario que los presupuestos y los documentos que acompañan sus liquidaciones contengan información adecuada y suficiente, de manera que se proporcione a todos los agentes implicados en el proceso económico la información adecuada para comprobar el cumplimiento de las normas que los rigen y de los objetivos que se pretende alcanzar.

Pues bien, es preciso analizar las distintas formas de colaboración público privada para comprobar si se adecuan a las exigencias que demanda la estabilidad presupuestaria desde la perspectiva de la plurianualidad. En este sentido, se podrá comprobar que algunos de los modelos, a nuestro juicio, sobrepasan los límites de los escenarios plurianuales previstos en la legislación vigente, y otros no permiten su verificación en tanto que no tienen reflejo ni en los presupuestos ni en los balances de las administraciones públicas que los utilizan, de manera que no es fácil saber la situación de las finanzas públicas.

En definitiva, una de las causas directas de la búsqueda de fórmulas alternativas de financiación de obras públicas, las limitaciones de la estabilidad presupuestaria, es también la que nos brinda el marco de programación plurianual para poder decidir cuáles son las necesidades prioritarias de gasto y la oportunidad de utilizar financiación privada para acometer algunas de ellas, ahora bien, entendemos que estas decisiones deben ser estudiadas, conocidas y comprendidas por sus protagonistas, y desarrolladas dentro del marco legal vigente de manera que no comprometan el gasto de ejercicios futuros al margen del marco plurianual 
establecido. En definitiva, es el modelo de estabilidad por el que hemos optado y en el que han de desarrollarse las actuaciones de los poderes públicos.

C. El control de las fórmulas de financiación con colaboración público-privada

Uno de los aspectos más relevantes de las fórmulas de colaboración público-privada en la financiación de obras públicas, y sin embargo la más descuidada es su control. En función de los objetivos del control sobre estas fórmulas podría diferenciarse entre el control de legalidad, el control contable, y el control de la calidad. En relación con éste último, las auditorias operativas previstas en nuestra legislación presupuestaria persiguen esta idea en tanto que tratan de corregir deficiencias incluyendo el control del cumplimiento de los principios de economía, la eficiencia y la eficacia. Ahora bien, en tanto que el cumplimiento de estos principios, así como la calidad en la prestación del servicio devienen en aspectos esenciales, se plantea la necesidad de que se verifique que las fórmulas de colaboración público-privada permitan que están enfocadas a la consecución de estos objetivos.

De cualquier modo, la parte más débil del fenómeno de las CPP es su control, en tanto que la rendición de cuentas es una de sus grandes deficiencias. En este sentido, la información, la publicidad y la transparencia a la que se ha hecho referencia sería un modo de poder controlar y conocer el proceso.

Por otra parte, el cambio operado en el sector público, en el que la calidad en la prestación de los servicios a precios razonables es una de las exigencias más relevantes, parece que se precisa un órgano que pueda encargarse de su control, bien sean agencias independientes, el propio Tribunal de Cuentas u órganos de ellos dependientes, aunque no es lo más importante, ya que lo verdaderamente relevante es que se arbitren los mecanismos suficientes para su consecución.

\section{CONCLUSIONES}

La coyuntura de crisis que actualmente atraviesa nuestro país nos obliga a retomar el debate sobre el modelo con el que queremos que se administren los intereses y necesidades públicas. Los mecanismos de 
colaboración con el sector privado y la implicación de todos los agentes sociales en la consecución del interés general tendrán probablemente gran protagonismo en la Administración del futuro, y por consiguiente, en la financiación de bienes y servicios públicos.

En el actual escenario económico y legislativo la Administración debe asumir un nuevo rol e implicar al sector privado y a los particulares en la financiación de las obras y servicios públicos. Es evidente que la colaboración público-privada es una realidad consolidada aunque en constante evolución, que abre nuevos caminos y que brinda nuevas oportunidades de financiación de obras públicas y de satisfacción de necesidades públicas.

Si bien en un primer momento las fórmulas de colaboración público-privada en nuestro país buscaban mayor flexibilidad en la gestión pública mediante la utilización de la colaboración institucionalizada, y en una fase más reciente, sortear las limitaciones que imponían los criterios de estabilidad presupuestaria -limitativos del déficit y del endeudamiento público-, pensamos que en el momento presente, caracterizado por una drástica reducción de los recursos públicos, uno de los objetivos de estos modelos es diferir pagos a presupuestos futuros, sin perjuicio de que en la medida de que se trate de obras susceptibles de explotación, su coste sea asumido por los usuarios de los servicios.

Ahora bien, aunque los mecanismos de ejecución y explotación de obras públicas se adecuen a las limitaciones financieras de las administraciones públicas, deben de buscar prioritariamente la eficiencia y la calidad en la prestación de servicios.

La legislación más reciente ha establecido las bases para acoger fórmulas de colaboración utilizadas en otros países y basadas precisamente en técnicas concesionales o en el diferimiento del pago de la obra durante su vida útil, convirtiendo así inversión en gasto corriente. El primer paso en este sentido fue la Ley 13/2003, de 23 de mayo, reguladora del Contrato de Concesión de Obra Pública, que abrió las puertas a la CPP no institucionalizada basada en contratos concesionales, y la Ley 30/2007, de Contratos del Sector Público, que ha constituido un hito esencial en esta tendencia de tipificación de la colaboración entre el sector público y privado al regular el contrato que bajo esta misma denominación facilitará la realización de proyectos que no son susceptibles de explotación comercial y en los que el coste no puede ser repercutido a los ciudadanos, debiendo ser asumido por la Administración. 
Desde nuestro punto de vista, este nuevo contrato de colaboración entre el sector público y privado permitirá a las Administraciones diferir y prorratear el pago de las obras a lo largo de la vida del contrato, estableciendo un procedimiento para su adjudicación en el que se recogen mecanismos, como la evaluación previa, que permiten introducir criterios de eficiencia en la contratación. Se trata de un paso importante en la incorporación a nuestra legislación de las técnicas de colaboración público-privada utilizadas en otros países y que modifica el rol de la Administración en la provisión de bienes y servicios, permitiendo la contratación de proyectos eficientes, ajustados a las necesidades de los ciudadanos y que proporcionan mayor calidad del servicio.

Todo lo expuesto nos lleva a concluir que estas nuevas fórmulas de acometer proyectos de colaboración con el sector privado deben analizarse de manera multidisciplinar desde la Economía financiera, el Derecho administrativo, la Contabilidad pública, y también por el Derecho financiero que no puede permanecer ajeno a esta realidad que afecta tanto a la vertiente de los gastos como a la de los ingresos públicos.

Estas fórmulas han alterado los sistemas de financiación tradicionales de obras públicas y los mecanismos para su pago, por lo que debemos asegurarnos que las fórmulas de colaboración público-privadas se desenvuelven en el ámbito de la justicia del sistema financiero que garantiza la Constitución Española.

Desde la perspectiva de los ingresos públicos hay que tener presentes varias cuestiones. Por ejemplo, hacer un uso excesivo del poder tarifario de la Administración -sin perjuicio de la consideración de tasa de las tarifas-, puede justificar un incremento de impuestos que no tenga en cuenta la contribución de los usuarios al coste de los servicios. Asimismo, puede conllevar un cambio en la estructura de los ingresos públicos e incluso obliga a plantearse la utilización de figuras tributarias poco utilizadas hasta ahora en la financiación de obras públicas como las contribuciones especiales. Tarifas, tasas, contribuciones especiales, lo que parece evidente que el principio retributivo comienza a ganar terreno al contributivo, aunque hay que matizar que esta ventaja no debiera afectar a la provisión de bienes y servicios públicos esenciales. El problema estará en la delimitación de este concepto.

Examinar las fórmulas de colaboración público-privada a la luz de los principios que informan el gasto público es una tarea prioritaria de la que se desprende la necesidad de un mayor desarrollo del Derecho 
de los gastos públicos. Este desarrollo daría respuesta a muchas de las cuestiones que plantea su financiación y asignación: cuál debe ser el recurso más adecuado para la financiación de las necesidades públicas en función de la política fiscal que se desarrolle, cuáles son las necesidades que es prioritario atender con recursos presupuestarios, cuáles son las infraestructuras en las que está justificado diferir el gasto a presupuestos futuros, y en definitiva, la consecución del mandato constitucional de que se realice una distribución equitativa del gasto público.

Desde nuestro punto de vista, la clave se encuentra en que sea la ley la de discipline el régimen jurídico del gasto público, una norma en la que debiera de regular la planificación de inversiones en obras públicas, su temporalidad, las vías para su financiación, ya que de este modo sería más fácil la consecución de una asignación equitativa de recursos públicos que no comprometiera los presupuestos de ejercicio futuros.

En este ámbito es esencial incrementar la transparencia y la información de la utilización de todas estas fórmulas, que requieren de un exhaustivo control por parte de la Administración que garantice la calidad en la cobertura de las necesidades públicas.

\section{BIBLIOGRAFÍA}

ACERETE GIL, J.B. (2004) Financiación y gestión privada de Infraestructuras y servicios públicos: Asociaciones público-privadas. Madrid: Instituto de Estudios Fiscales.

AlBIÑANA GarCíA-QuintANA, C. (1979) Derecho Financiero y Tributario. Madrid: Ministerio de Hacienda, Escuela de Inspección Financiera y Tributaria.

BAYONA DE PEROGORDO, J.J. (1979) "Notas para la construcción de un Derecho de los gastos públicos", Presupuesto y Gasto Público, 2, pp. 65-80.

- (1982) "El procedimiento de gasto público y su control", Presupuesto y Gasto Público, 13, pp. 27-36.

- (1991) El Derecho de los gastos públicos. Madrid: Instituto de Estudios Fiscales.

Blasco Delgado, C. (2008) "La colaboración del sector privado en la financiación 'interpresupuestaria' de infraestructuras públicas en España", R. FAlCón Y TelLA (dir.) Análisis jurídico de los mecanismos de 
financiación de las infraestructuras públicas. Madrid: Instituto de Estudios Fiscales.

Calvo ORTEGa, R. (2003) "La tasa por utilización de autovías en la Unión Europea", Nueva Fiscalidad, 7, pp. 9-17.

- (2008) Curso de Derecho financiero. Derecho Tributario, $12^{\mathrm{a}}$ Edición. Cizur Menor (Navarra): Civitas.

Cayón Galiardo, A. (1988) La unidad funcional de la Hacienda Pública. Madrid: Instituto de Estudios Fiscales.

- y J.M. ALMUDí CID (2008) "La posición del Usuario ante las modalidades de financiación de los servicios públicos prestados por la iniciativa privada", R. FALCón Y TelLA (dir.) Análisis jurídico de los mecanismos de financiación de las infraestructuras públicas. Madrid: Instituto de Estudios Fiscales.

CAZORLA PRIETO, L.M. (1979) Incidencia de la nueva Constitución en la legislación territorial tributaria. Madrid: Instituto de Estudios Fiscales.

CONSUlTORES DE LAS AdMINISTRACIONES PÚBliCAS (2004) El uso de la figura concesional en la financiación de obras, 145.

DORREGO de CARLOS, A. y F. MARTínez VÁZquez (2009) "La colaboración público-privada". A. DORREGO DE CARLOS y F. MARTínEZ VÁZQUEZ (dirs.) La colaboración público-privada en la Ley de Contratos del Sector Público: Aspectos administrativos y financieros. Madrid: La Ley.

FALCón Y TELLA, R. (2004) "Las tasas y peajes por el uso de infraestructuras Directiva 'Euroviñeta' ¿contraposiciones o medidas fiscales?", Revista de Derecho Comunitario Europeo, 19, pp. 907-916.

Folgado Blanco, J. y A. SÁnChez Soliño (1999) "La Política Presupuestaria y la financiación de las infraestructuras en España", Revista de Obras Públicas, 3.391, pp. 11-28.

FUENTES FERNÁNDEZ, A. (2007) "Fundamentos de la colaboración públicoprivada para dotación de infraestructuras y servicios", Revista de Derecho de las Telecomunicaciones e Infraestructuras en red, 29, pp. 37-124.

García de ENTERRía, E. (1953) "Sobre la naturaleza de la tasa y las tarifas de los servicios públicos", Revista de Administración Pública, 12, pp. 129-160.

García NovoA, C. (2001) "Fundamento de la Ley de Estabilidad Presupuestaria", Presupuesto y Gasto Público, 27, pp. 147-166.

García-Herrera Blanco, C. y M.A. Grau Ruiz (2008) "Reflexiones sobre el carácter tributario de las cantidades cobradas por la prestación de servicios públicos en régimen de concesión", R. FALCón Y TELLA (dir.) 

público-privada en la financiación de obras y servicios públicos en España

Análisis jurídico de los mecanismos de financiación de las infraestructuras públicas. Madrid: Instituto de Estudios Fiscales.

GonzÁlez García, J.V. (2008) "El riesgo del concesionario como elemento central de las concesiones de obra pública", R. FALCÓN Y TELLA (dir.) Análisis jurídico de los mecanismos de financiación de las infraestructuras públicas. Madrid: Instituto de Estudios Fiscales.

GUTIÉRREZ FRANCO, Y. (2008) "Las asociaciones público-privadas desde la perspectiva de la economía pública", R. FALCón Y TELLA (dir.) Análisis jurídico de los mecanismos de financiación de las infraestructuras públicas. Madrid: Instituto de Estudios Fiscales.

JIMÉNEZ DE CISNEROS CID, F.J. (1999) "Hacia un nuevo concepto de infraestructura pública/obra pública desligado del dominio público y del servicio público", Anuario de la Facultad de Derecho de la Universidad Autónoma de Madrid, 3, pp. 195-201.

JIMÉNEZ DíAZ, A. (2009) "Técnicas contractuales de colaboración públicoprivada (II): el contrato de colaboración público-privada en la nueva Ley de Contratos del Sector Público", A. DORREGO DE CARLOS y F. MARTÍNEZ VÁZQUEZ (dirs.) La colaboración público-privada en la Ley de Contratos del Sector Público. Aspectos administrativos y financieros. Madrid: La Ley.

JUAN LOZANO, A. (2008) "La financiación de infraestructuras y el gasto público", R. FAlCón Y TelLA (dir.) Análisis jurídico de los mecanismos de financiación de las infraestructuras públicas. Madrid: Instituto de Estudios Fiscales.

- y J. ROdRÍGUEZ MÁRQUEZ (2006) La colaboración público-privada en la financiación de las infraestructuras y servicios públicos. Una aproximación desde los principios jurídico-financieros. Madrid: Instituto de Estudios Fiscales.

Lozano Serrano, C. (1998) "Las prestaciones patrimoniales públicas en la financiación del gasto público", Revista Española de Derecho Financiero, 97, pp. 25-52.

MARí OlANO, J. (2009) "Técnicas contractuales de colaboración públicoprivada (I): el contrato de concesión de obra pública", A. DORREGO DE CARLOS Y F. MARTíNEZ VÁZQUEZ (dirs.) La colaboración público-privada en la Ley de Contratos del Sector Público. Aspectos administrativos y financieros. Madrid: La Ley.

MARTín QUeRALT, J. (1980) "La Constitución española y el Derecho financiero", Hacienda Pública Española, 63, pp. 97-131. 
MARTíneZ Calvo, J. (2005) "Hacia la construcción de un 'Derecho Administrativo Financiable'. Crónica del Caso Mintra", Revista de Administración Pública, 167, pp. 369-402.

ORÓN MORATAL, G. (1995) La configuración constitucional del gasto público. Madrid: Tecnos.

- (2001) "Sobre la financiación de infraestructuras hidráulicas y el principio de recuperación de costes", Revista Valencia de Economía y Hacienda, 3, pp. 9-21.

Palomar Olmeda, A. (2005) "La doctrina sobre las tarifas portuarias: un nuevo paso en la lenta reconquista para el Derecho público de la acción administrativa", Repertorio de Jurisprudencia Aranzadi, 7, pp. 21629-21636.

RAmírez CUEVAS, G. (2008) "La colaboración (asociación) público-privada como mecanismo de financiación de las infraestructuras públicas en el ámbito de la Unión Europea", R. FALCón Y TELLA (dir.) Análisis jurídico de los mecanismos de financiación de las infraestructuras públicas. Madrid: Instituto de Estudios Fiscales.

RUIz GarIJO, M. (2002) Problemas actuales de las tasas. Valladolid: Lex Nova.

- (2005) "Tarifas exigidas por la prestación de servicios públicos: por fin tasas y no precios privados. La esperada doctrina del Tribunal Constitucional", Nueva Fiscalidad, 7, pp. 79-94.

- (2008) "El principio del beneficio en la financiación de determinadas infraestructuras: idoneidad de las tasas, contribuciones especiales y peajes", R. FAlcón y TelLA (dir.) Análisis jurídico de los mecanismos de financiación de las infraestructuras públicas. Madrid: Instituto de Estudios Fiscales.

RUIz OJEDA, A. (2000) "Aplicaciones en materia de financiación privada en España: entre la financiación diferida y las fórmulas concesionales", A. RUIZ OJEDA, G. MARCOU, J. GOH, La participación del sector privado en la financiación de infraestructuras y equipamientos públicos: Francia, Reino Unido y España (Elementos comparativos para un debate). Madrid: Civitas, pp. 133-211.

SANTOS SABRÁS, M. (2000) "La situación actual de España y la necesidad de definir un modelo coherente", La financiación de infraestructuras: nuevos desafíos y exigencias. Santander: Universidad Internacional Menéndez Pelayo.

SerRa, M. y R. Buenaventura (2003) "El uso de la figura concesional en la financiación de obras", Revista de Análisis Local, 51, VI, pp. 5-14. 
VALCÁRCEL FERNÁNDEZ, P. (2006) Ejecución y financiación de obras públicas. Estudio de la obra pública como institución jurídico administrativa. Madrid: Thomson-Civitas.

- (2007) "Fórmulas alternativas de financiación de infraestructuras públicas. Experiencias de colaboración público-privada", en las Jornadas sobre la iniciativa privada en la financiación de proyectos públicos. Universidad de Burgos. 